\title{
MICROSTRUCTURAL STABILITY OF PYROMET 860 IRON-NICKEL BASE HEAT RESISTANT ALLOY
}

\author{
G. N. Maniar, D. R. Muzyka, C. R. Whitney
}

\section{Abstract}

Previous results showed that Pyromet 860 , an iron-nickel base heat resistant alloy is stable at temperatures as high as $1500^{\circ} \mathrm{F}$ for aging times as long as 100 hours. It was desired to have longer time data. In the present work, samples from four production heats were subjected to long time creep/rupture testing at 1050 to $1400^{\circ} \mathrm{F}$ at different stress levels. Times as long as 37,660 hours were employed. The effects of time, temperature and stress on the precipitates and their morphologies were studied by optical and electron microscopy, $X$-ray and electron diffraction and microprobe techniques. $\mathrm{Mu}$ phase, containing $\mathrm{Co}, \mathrm{NI}$ and $\mathrm{Mo}$, was detected in Pyromet $860^{\circ}\left(\mathrm{NvSS}_{\mathrm{S}}=2.40-2.45\right)$ after extended exposures from $1200^{\circ} \mathrm{F}$ to $1400^{\circ} \mathrm{F}$, and careful study was performed to describe the kinetics of its formation in this alloy. A previously unreported phase, which is speculated to be a transition phase preceding $\mathrm{Mu}$ phase formation, was also detected. This phase has been tentatively indexed to be hexagonal. Mu phase formation apparently has little effect on the elevated temperature properties of Pyromet 860 . For times as long as 500 hrs. at $1300^{\circ} \mathrm{F}$ and below, with Mu phase detected, no significant effects on ambient temperature properties are noted. For longer times at $1300^{\circ} \mathrm{F}$ and after $1400^{\circ} \mathrm{F}$ exposure, effects of $\mathrm{Mu}$ phase formation on ambient temperature tensile strength properties are not clear due to gamma prime effects. Ductility changes under such conditions apparently depend on exposure stress. Grain boundary reactions may also have an effect.

Authors are associated with The Carpenter Steel Company, Research and Development Center, Reading, Pa. 
Introduction

In the selection of alloys for use in gas turbine applications, structural stability ranks as a primary criterion. High elevated temperature strength and cost are also of major concern. With these factors in mind, Pyromet 860 alloy, an iron-nickel-base superalloy was designed. This alloy combines the cost advantages of iron-nickel-base alloys such as A-286, 901 and $V-57$ with improved strength and structural stability. Specifically, from a study (1) of the effects of cobalt, titanium and aluminum on a base of .05 C, 12-13 Cr, 43.0 Ni, $6.0 \mathrm{Mo}$ and balance $\mathrm{Fe}$, Pyromet 860 evolved as an alloy with strength in the range of the more expensive nickel-base superalloys (2) and no tendency to form the cellular, hexagonal eta ( $\mathrm{Ni}_{3} \mathrm{Ti}$ ) phase common to the alloys of the $\mathrm{A}-286,901$ and V-57 types. (1) The effects of eta in embrittling and/or weakening these alloys depending on distribution and amount are well known.

The excelient high temperature properties of Pyromet 860 in its useful range $\left(1000^{\circ} \mathrm{F}-1400^{\circ} \mathrm{F}\right)$ are attributed to the presence of cobalt in the alloy as well as the stable nature of the gamma prime phase present. The tendency of the precipitated phase - gamma prime - in this alloy to remain in the desirable FCC form and to show no propensity to transform to the "overaged", hexagonal eta (Ni $3^{\mathrm{Ti}}$ ) is attributed to the optimum titanium-aluminum balance of the alloy. A previous study (3) reported on the stability of Pyromet 860 at temperatures from $1375^{\circ} \mathrm{F}$ to $1575^{\circ} \mathrm{F}$ and times up to 100 hours. That study showed that the gamma prime particles increased in size and separation and decreased in number. with an increase in time or aging temperature. No deleterious phases were found to occur. In the present work, samples from four production heats were subjected to long time creep/ rupture testing at primarily 1050 to $1400^{\circ} \mathrm{F}$ at different stress levels. Various heat treatments were used on the starting samples and tests were run as long as 37,660 hours. The effects of time, temperature and stress on the precipitates and their morphologies were studied by optical and electron microscopy, X-ray and electron diffraction and microprobe techniques. Electron-vacancy number, Nv, calculations were made by TRW. (4) Experimental results are correlated with the Nv data used to predict occurrence of intermetallic phases such as sigma phase.

\section{Experimental Procedure}

Mechanical Tests:

Material for the present study came from four production size heats of Pyromet 860 alloy, welghing from about 3,000 pounds to about 10,000 pounds. All of these heats were made by vacuum induction melting plus consumable electrode vacuum remelting. The nominal analysis for this alloy 
is compared with the actual analyses of the four heats in

Table I.

By way of various forging sequences, sections of these heats were processed to $9 / 16^{\prime \prime}$ round bar, $3 / 4^{\prime \prime}$ square bar, $3 "$ round bar, 4" square bas and a gas turbine blade forging about $16^{\prime \prime}$ long, about $6^{\prime \prime}$ wide and weighing about 20 pounds. In general, all forging of this alloy is done from a $2050^{\circ} \mathrm{F}$ furnace temperature.

Longltudinal test blanks were cut from the centers of the smaller bars, from mid-radius positions for the $3^{\prime \prime}$ and 4 " bars and from the alrfoll of the gas turbine blade and heat treated according to the procedures outlined in Table II. Heat treatment "A" is the "standard treatment" recommended for this alloy for best all-around strength and ductility. Heat treatment " $B$ " is a modification of treatment "A" for improved tensile strength at moderate temperatures. The treatment coded "C" was designed for treating large sections according to a procedure previously described. (5) Heat treatment "D" was developed to yield optimum stress relaxation characteristics at $1050^{\circ} \mathrm{F}$ for a steam turbine bolting application.

After heat treatment, the test blanks were machined to either piain bar creep specimens with a gage diameter of $0.252^{\prime \prime}$, to combination smoothonotched stress-rupture bars with a plain bar diameter of $.178^{\prime \prime}$ and a concentration factor of $\mathrm{Kt} 3.8$ at the notched section, or to notch-only specimens. All specimens conformed to ASTM requirements. Creep-rupture tests were then performed in ordinary Arcweld (or Satec) stands employing three-zone temperature monitoring and center zone control. Some of the present results have been discussed elsewhere. (6) For tests lasting less than 10,000 hours, no detectable temperature variations or control problems were experienced. For the longer time tests, a few problems were encountered. These are documented in the section dealing wth results, below.

Metallography:

Most of the creep-rupture tests were continued to failure. A few bars were fractured as smooth or notch tensiles after creep-rupture exposures. After fracturing, ordinary metallogxaphic sections were made primarily in gage areas adjacent to fractures to represent a "high stress" region and through specimen threads to represent a "Iow stress" region. Al1 metallographic specimens were made in a longitudinal direction with respect to the test specimen axes. For optical microscopy, the samples were etched in glyceregia ( $15 \mathrm{ml} \mathrm{HCl}, 5 \mathrm{ml} \mathrm{HNO}_{3}, 10 \mathrm{ml}$ glycerol). For X-RD analysis, the phases were extracted electrolytically in two media:

$20 \% \mathrm{H}_{3} \mathrm{PO}_{4}$ in $\mathrm{H}_{2} \mathrm{O}$ for selective extraction of gamma prime and $10 \% \mathrm{HCl}$ in methanol for carbides and other phases. Electron microscopy studies consisted of two phases:

(i) Structure analysis using chromium shadowed parlodion replicas prepared from samples etched in "G" etchant electrolytically. "G" etchant is a mixture of $12 \mathrm{ml}$ 
$\mathrm{H}_{3} \mathrm{PO}_{4}, 47 \mathrm{ml} \mathrm{H}_{2} \mathrm{SO}_{4}$ and $4 \mathrm{ImI} \mathrm{HNO}_{3}$. This etchant is selective and does not attack the gamma prime precipitate in Pyromet 860 alloy.

(ii) Selected area electron diffraction analysis of precipltates extracted on a carbon substrate. The carbon extraction replicas were prepared by etching the sample in glyceregia, vacuum depositing carbon, scribing the carbon fllm and re-etching the specimen electrolytically in $10 \% \mathrm{HCl}$ in methanol to lift off the carbon replica. It is known from previous experience (3) that glyceregia attacks the gamma prime precipitate in heat treated Pyromet 860 revealing the grain boundary precipitates and other intermetaliic phases for diffraction analysis.

Nv Calculations:

It was decided to determine all ten $\mathrm{NV}$ numbers recently studied by TRW. (7) For this purpose, compositions representative of the samples studied were submitted to TRW. The NV calculation recommended for this presentation, $\mathrm{Nv}_{S S}$, is the same as $\mathrm{Nv}_{5}$ of the work by Collins, et al. (7)

\section{Experimental Results}

Mechanical. Properties:

Tensile Tests. In order to characterlie the effects of the various heat treatments on the properties of Pyromet 860 , tensile data representative of the various heat treated conditions are given in Figure 1. The data presented represent strength values for several heats and are believed to be typical of the effects of the various heat treatments on the properties of Pyromet 860 . The most complete data are for heat treatment "A", the "standard treatment" for this alloy. Data for the other treatments are not as complete. The difference of greatest consequence noted in these data is the higher strength and concomitant lower ductility noted for treatment $B$. This is, of course, related to the final $1200^{\circ} \mathrm{F}$ age incorporated in this treatment. Apparently, this treatment yields a critical distribution of gamma prime such that this higher strength can be realized. Specimens for treatment $D$ also show ductility values below those for treatment A. This may be related to the fact that all of the tests for treatment $D$ came from relatively large bar ( 3 ". diameter) or due to the $1250^{\circ} \mathrm{F}$ final age.

Stress-Rupture Tests, Stress-rupture tests ranging from $850^{\circ} \mathrm{F} 7165 \mathrm{ks}$ to $1500^{\circ} \mathrm{F} / 35 \mathrm{ksi}$ were run on the various forms and heats for the various heat treated conditions. Most specimens were smooth/notch combination specimens ( $K_{t} 3.8$ ). Test data are listed in Table III. Using these data, Figure 2 was constructed to show the effects of heat treatment on the stress-rupture properties of Pyromet 860 . It should be noted that although notch data are not in abundance, all tests listed in Table III (except those so indicated) were 
for specimens containing both smooth and notch ( $X_{t} 3.8$ ) sections. Thus, each test lmplies notch ductility. Some of these stress rupture results plus the long-time creep data to be considered below, have been discussed elsewhere. (6)

As a demonstration of the notch ductility of Pyromet 860 , Figure 2a shows data up to (Larson-Miller Parameter) PLM=41. 4, for heat treatment "A". An obvious and comfortable separation of the notch and smooth curves can be seen. In Flgure 2b, smooth bar data for all four heat treatments are given. The data overlap somewhat due to the various configurations and grain structures tested. It is felt that for practical purposes, heat treatments $A, B$ and $C$, produce essentially the seme strength and ductility properties. However, weatment "D" produces reduced life with an increase in ductility. This treatment was designed for optimum stressrelaxation properties for Pyromet 860 at $1050^{\circ} \mathrm{F}$. (6) Long-Iime Creep Tests. Three extremely long-time creep tests were conducted. Data for these tests are given in Table IV and plotted in rigure 3. These tests took up to 4 years to complete and were interrupted several times due to power Palures, replacing of thermocouples periodically and fos movang of test equipment. The accidents of long-time testing are recorded in the table and on the plot. It has already been demonstrated in the Itterature (6) that these long time data were, for all practical purposes, predicted by the relatively shorter time Larson-Milier data given for treatment "A" in Figure $2 \mathrm{~b}$.

3tability Tests. A few of the exposed stress-rupture and oreep specimens were fractured as room temperature tensiles. Data of this type are given in Table $V$, along with comparable data for unexposed but similarly heat treated samples. As can be seen from this relatively small amount of date sxposures of up to 5700 hrs. at $1050^{\circ} \mathrm{F} / 96 \mathrm{ksi}$ have no effect on roon temperature notch tensile strength for Pyromet 860. Conversely exposures of 671 and $1124 \mathrm{hrs}$. at $1350^{\circ} \mathrm{Fl}$ $50 \mathrm{ksi}$ reduced room temperature notch tensile strength by about $25 \%$. The extremely long exposures of over $37,000 \mathrm{hrs}$. at $1200^{\circ} \mathrm{F} / 50 \mathrm{ksI}$ and over $33,000 \mathrm{hrs}$ at $1400^{\circ} \mathrm{F} / 15 \mathrm{ksi}$ have reduced smooth room temperature strength and ductility by a considerable amount. The prior creep deformation for these specimen: was $2.89 \%$ and $5.1 \%$, respectively.

Metal Jographic Studies:

Flgure 4 shows a typlcal as-heat-treated optical microstructure Por Pyromet 860 alloy. This structure consists of a somewhat duplexed grain $\mathrm{size}$ and some light stringers of $T I(C, O, N)$. Grain boundary carbides are not easily resolved on the light microscope. There are no major differences in the Iight microstructure of this alloy with the various heat treatments.

The more salient features of the microstructure of an austenitic superalloy are revealed by electron metallography. Pigure 5 shows representative electron micrographs of Pyromet 860 for the various heat treatments and heats studied. 
The basic microstructure is very similar for all heats and heat treatments. All show a fine dispersion of spheroidal gamma prime and grain boundary precipitates identified as primarily $\mathrm{M}_{23} \mathrm{C}_{6}$ carbides. A few grain boundaries show zones denuded of gamma prime around them which may be due to the coarse $\mathrm{Cr}-\mathrm{rich}\left(\mathrm{M}_{23} \mathrm{C}_{6}\right)$ grain boundary carbides. These carbides may cause localized $\mathrm{Cr}$ depletion near the grain boundaries and subsequent increased solid solubility for AI in the iron-nickel austenite matrix.

There is relatively little difference in the gamma prime size and spacing for treatments $A, B$ and $C$. However, treatment $D$ gives a relatively coarser particle size. The following measurements have been made from extraction replicas:

Heat Treatment

B
C
D

Average Gamma Prime Particle Size

$300 A^{\circ}$
$360 A^{\circ}$
$300 A^{\circ}$
$570 A^{\circ}$

The relatively coarse particle size produced by treatment $D$ does affect mechanical properties, as was indicated above. These, as well as other heat treatments for Pyromet 860 have been designed using the Larson-Miller parameter approach (5) to get desired gamma prime sizes and distributions for various strength requirements.

For exposed samples, as has been indicated above, metallographic specimens were made in both thread ( $1 . e$., no stress to low stress) areas and gage (high stress) areas. It was noted that the usual difference between a thread and gage section was that the gage (stressed) area showed a greater propensity for a phase to form. The results below are for thread areas - except where stated otherwise.

Specimens exposed at $1050^{\circ} \mathrm{F}$ were for heat treatment $D$, the steam turbine bolting treatment. No effects of exposures up to 5716 hours at stresses up to $96 \mathrm{ksi}$ on $11 \mathrm{ght}$ microstructure were observed.

For the electron microstructure, Figure 6 shows that exposures up to 5716 hours cause some agglomeration (and elongation) of grain boundary carbides, a small amount of filmy precipitates, a small amount of grain boundary gamma prime, possibly related to a reaction of the type: (8)

$$
\gamma+\mathrm{MC}-\rightarrow \mathrm{M}_{23} \mathrm{C}_{6}+\gamma^{\prime}
$$

and a few grain boundaries with areas devoid of gamma prime. The matrix gamma prime in these specimens appears, in general, to remain uniform with a particle size approximately equivalent to that of the as-heat-treated samples. No needle or plate-iike precipitates were seen. However, in the 5716 hour sample, vague evidence of gamma prime particles iningup (possibly an "Inclplent needle") was noted in a few areas (Figure 6d, lower right corner). This was not noted at 4709 hours.

At $1100^{\circ} \mathrm{F}$, specimens for treatments $A, B$ and $C$ were observed after exposures of up to 3967 hours. Light micrographs in Figures 7 and 8 show that with increasing time to 2955 hours at $1100^{\circ} \mathrm{F}$, slight agglomeration of grain boundary 
phases and grain boundary widening occurs. After 3967 hours, appreciable grain boundary widening is apparent, and some evidence of formation of continuous grain boundary phase is seer. Evidence of precipitation of a phase not previously seen in this alloy on apparent octahedral planes (or "slip lines") of the parent austenite was noted in the 2955 and 3967 specimens in the gage length (highly stressed) areas only. An example of this structure is shown in Figure 9 for the 3967 hour specimen.

Figures 7 and 8 also show electron microstructures of samples after exposures at $1100^{\circ} \mathrm{F}$, up to 3967 hours. A comparison of gamma prime size shows no difference as a function of time at $1100^{\circ} \mathrm{F}$, from 1037 to 3967 hours. Also, as compared to Higures $5 a, b, c$, the gamma prime of these samples is similar in size, packing and morphology to equivalent unexposed samples. The grain boundary precipitates may have coarsened with time at $1100^{\circ} \mathrm{F}$, but not a great deal. As was the case at $1050^{\circ} \mathrm{F}$, a few regions of filmy grain boundary phases: grain boundary gamma prime, as well as grain boundary regions denuded of gamma prime can be noted. Differences of these features with respect to time at temperature were not very great.

During light microscopic observation of the 2955 and 3967 hour specimens - gage areas (stressed)-the incipient formation of a new phase was noted on "slip lines" of the parent austenite. This phase was indexed by $X-r a y$ diffraction techifues to be an unknown phase rich in Fe, Ni, Cr, Co. It was tentatively identified as an hexagonal phase. Further work is being done to characterize it. The "d" spacings of this phase are compared with published values for Ni3Ti in Table VI. Duxing electron microscopic studies, no distinct phase was seen in these samples. It is hypothesized that this "unknown phase" may be a transition phase proliminary to Mu phase formation, to be discussed below.

At $1200^{\circ} \mathrm{F}$, only one specimen was examined after a creep exposure for 37,660 hours at $50 \mathrm{ksi}$. Treatment A was used for this test. This specimen, Figure 10a, showed continuous gresin boundary precipitation, including a phase with a needlewike" arpearance in two dimensions, growing from the grain boundaros into the grains along apparent octahedral planes. For the coarser grains, centers are devoid of this phase. For the finer grains; the "needle-like" phase has spread neariy throughout some of these grains in an apparent octahedral (or "fir-tree") arrangement with respect to the parent austenite matrix. The structural replica electron micrographs in Figure 10 show that this exposure has coarsened the gamma prime slightly. The extraction replica micrograph shows that, in three dimensions, the "needle-like" phase is trujy platelet in nature. As will be discussed below this phase was identified as (Co, Ni, Mo) Mu phase. Figure 11 shows a moroprobe $X$-ray scanning microphotograph indicating the Momenrichment in the Mu phase relative to the matrix. 
Figure 12 shows the microstructure for a sample exposed for 14,230 hours at $1300^{\circ} \mathrm{F} / 35 \mathrm{ksi}$. Treatment $A$ was used for this specimen also. This specimen was overheated for a short perlod to $1400^{\circ} \mathrm{F}$ and discontinued with a total creep elongation of 11.7\%. It is believed that the short $1400^{\circ} \mathrm{F}$ "overheat" had little or no effect on the microstructure. This specimen shows, to a lesser degree, the same microstructural features as the 37,660 hour specimens at $1200^{\circ} \mathrm{F}$.

At $1350^{\circ} \mathrm{F}$, specimens for treatments $\mathrm{A}$ and $\mathrm{C}$ were examined after 671 and 1124 hours, respectively, at a common stress of $50 \mathrm{ksi}$. Light micrographs in Figure $13 \mathrm{a}$ and $14 \mathrm{a}$ show that the thread areas of these samples contain heavy grain boundary precipitation and agglomeration. In addition, incipient formation of the platelet-like precipitate is seen. That is especially noted in the stressed area of the 1124 hour sample, Figures I4c and d. Electron micrographs for these specimens are also shown in Figures 13 and 14 . The gamma prime precipitate particle size has been slightly coarsened by exposure. Also, the interparticle spacing has increased slightly. Very little depletion of gamma prime around grain boundaries has occurred. Also noted for the 1124 hour specimen, Figure $14 \mathrm{~b}$ - is an agglomeration of gamma prime particles near a few grain boundaries. The random, incipient plateletlike precipitate in the 1124 hour specimen is Mu phase. Again, the extraction replica electron micrograph shown in Figure $14 \mathrm{e}$ indicates the platelet-like nature of the Mu. Samples were observed after 541 and 33,222 hrs at $1400^{\circ} \mathrm{F}$. Treatment A was used for these tests. The 541 hour sample showed grain boundary agglomeration and some evidence of the platelet-like phase, Figure 15. The 33,222 hour specimen showed discrete, wavy grain boundary precipitates as well as a uniform intragranular distribution of the plateletlike precip1tate, Figure 16. Figure 16a shows a Mu phase distribution typical of that shown by collins et al ( 7 ) for other alloys (1.e., INCO 901, Rene' 41 and AF-21D).

The electron microstructures of these samples indicate gamma prime coarsening due to the 33,222 hour exposure. Also, extremely large lu phase platelets are evident throughout the matrix. High magnification studies (Figure 16) indicate that gamma prime particles appear to line-up along side of the Mu needles, or possibly, that the Mu platelets tend to grow between gamma prime particles. Also, the alloy responds to the etching reagent differently than in the as-heat-treated condition. These observations indicate that Mu phase forms from matrix elements. Once again, the extraction replica electron micrograph shown in Figure $15 \mathrm{~b}$ demonstrates the platelet nature of the Mu phase.

As has been Indicated above, the platelet-like (as seen in 3-dimensions or needle-like as seen in 2-dimensions) precipitate for micrographs shown in Figures $102(37,660$ hrs at $\left.1200^{\circ} \mathrm{F}\right), 12\left(14,230 \mathrm{hrs}\right.$. at $\left.1300^{\circ} \mathrm{F}\right), 13$ and 14 (671 and 1124 hrs. at $1350^{\circ} \mathrm{F}$ ), 15 and 16 (541 and 33,222 hrs at $1400^{\circ} \mathrm{F}$ ), was identified by X-ray diffraction and electron diffraction to be Mu phase. Apparently, this phase precipitates as a 
function of time and temperature. Time is critical as can be seen by comparing the vague evidence of $\mathrm{Mu}$ due to 671 and $1124 \mathrm{hr}$. exposures at $1350^{\circ} \mathrm{F}$ (Figures 13 and 14 ) with the profuse amount in a specimen exposed for 37,660 hrs. at $1200^{\circ} \mathrm{F}$ (Figure 10a). The effect of temperature can be seen by noting the variations in distributions for 33,222 hours at $1400^{\circ} \mathrm{F}$ (Figure 16) with that for 37,660 hours at $1200^{\circ} \mathrm{F}$ (Figure 10a).

Further X-ray diffraction analyses showed the new phase which was found on apparent octahedral planes (or "slip Iines") of the parent austenite for the 2955 and 3967 hour specimens at $1100^{\circ} \mathrm{F}$ (Figure 9). to be an hexagonal phase containing $\mathrm{Fe}, \mathrm{Ni}, \mathrm{Cr}$, and $\mathrm{Co}$. The "d" spacings of this phase are given in Table VI. This phase has also been detected in INCO 901 alloy. (9)

Mu Phase Kinetics:

Based upon these observations on the occurrence of $\mathrm{Mu}$ phase, a preliminary plot of $\mathrm{Mu}$ phase formation kinetics in Pyromet 860 alloy was made. The data for the samples discussed above are represented by the encircled points on Figure 17. The data to this point indicated that Mu phase formation was primarily a function of time and temperature. Stress effects appeared to be minimal. This is in agreement with results by collins et al on Rene' 41. (7) On the basis of this result, it was decided to use primarily thermal exposure data to establish more accurately the time-temperature behavior of Mu phase formation in this alloy. It appeared from the results presented above that, for the present heats, chemistry and/or heat treatment had little effect on the propensity to form Mu once "critical" time and temperature relationships were attained. Therefore, it was decided to concentrate this aspect of the study on one heat, number 3 , in Table I and one heat treatment, "A", in Table II.

After the exposures described in Table VII, specimens were fractured as tensile specimens at room temperature or at the temperature of exposure. These tensile test results are also listed in Table VII. Subsequently, the specimens were examined metallographically, especially for indications of $\mathrm{Mu}$ phase formation.

With the incorporation of the data of Table VII into Figure 17, a good approximation to the kinetics of Mu phase formation in Pyromet 860 is possible. As can be seen from Figure 17 , below $1300^{\circ} \mathrm{F}$ the data are not complete enough to fix the time-temperature relationships for occurrence of Mu. Exposures to establish the location of this curve are underway. These data should be available by the date of the oral presentation of this paper.

Nv Calculations:

Finally, the chemistries of the subject heats were analyzed according to procedures described in the literature by Collins et $a l$ ( 7 ) and ten Nv numbers calculated for each heat. These results are given in Table VIII. Variations 
among the heats evaluated were small, lndicating that all should have approximately equivalent tendencies to form phases controlled by electron/atom relationships. It is interesting to note that $\mathrm{NV}_{1}$ in Table VIII corresponds to the PHACOMP technique of Woodyatt, Sims and Beattie (10) and $\mathrm{Nv}_{2}$ corresponds to that described by Boesch and Slaney. (11) The other numbers are calculated via ramifications of these two basic methods, described in the literature by collins, et al. (7)

\section{Discussion}

Mechanical Properties:

It is well known that for austenitic high temperature alloys, much strength is derived from the dispersion of gamma prime precipitate produced by proper alloying and suitable heat treatment. For the present heats of Pyromet 860 , and the type of heat treatments studied (i.e., relatively high solution treatment temperatures), it is felt that the strengths of these heats should be about the same. Only heat 2 , with the highest Mo level $(6.24 \%)$ and highest Ti+Al $(4.34 \%)$ shows strength consistently higher than the other heats. This heat also has the highest Nv numbers. However, since the major interest of this paper is structural stability, chemistry relationships for Pyromet 860 will not be discussed further here.

For the varlous heat treatments employed, Figure 5 shows that the gamma prime particle size and distribution for all treatments except $D$, is about equal. Measurements on extraction replicas show that values of about $300 \mathrm{~A}^{\circ}$ are typical for treatments $A, B$ and $C$, while about $570 A^{\circ}$ is typical for treatment $D$. It is somewhat perplexing that the small difference in gamma prime size and distribution notable for heat treatment $B$, Figure 5b, is the only known apparent variable to account for the strength increase noted for treatment B in Figure 1. However, these strength differences are only about 8\%. Apparentiy, small differences in gamma prime distribution and size can account for such differences. It is also somewhat surprising that specimens heat treated to treatment $D$ are as strong as those treated to treatment $A$. However, the final $1250^{\circ} \mathrm{F}$ age in treatment $D$ can account for this.

Converse to the case for short time mechanical tests of Pyromet 860 , the data in Figure $2 \mathrm{~b}$ show that reasonable relationships between gamma prime size and distribution and stress-rupture strength do exist. At least treatments $B$ and $C$ with the finer gamma prime show the best strength. Treatment $A$ is intermediate, and treatment $D$, with the large gamma prime produces the weakest structures. Treatment D also produces the best rupture ductilities.

Stability Tests:

Tables V and VII show stability test data for Pyromet 860. That is, data for specimens fractured in short-time tension after extended high temperature exposure. Quite 
simply, the stability behavior of such alloys may be related to (i) formation of Intermetaliic phases or (ii) overaging of the gamma prime precipitate which results in coarsening of the gamma prime and changes in interparticle spacing. "Instability" covers all cases for which strength is decreased or increased appreciably and ductility is lowered appreciably by exposure.

Strength loss may occur in this type alloy due to the overaging of gamma prime or due to formation of incongruous phases; for example, due to loss of solid solution strengthening elements from the metal matrix. For the present data, two cases should be considered, that for strength loss (or gain) at the test or exposure temperature and that for strength loss (or gain) at room temperature. At Elevated Temperatures. It has already been shown in the Iiterature (6) that the Iong-time test data in Tables III and IV when superimposed on a curve of the type given in Figure $2 b$, indicate that relatively short-time stress-rupture test data (i.e. tests $<1000$ hrs.) can be used to reasonably predict relatively long-time stress-rupture data (tests >

1,000 hrs.) for Pyromet 860. Even in cases where the present work has shown formation of Mu phase, the stress-rupture data fit quite well the strength curves given in Figure $2 \mathrm{~b}$. It is also interesting to note that all. such samples, in addition to demonstrating good strength also demonstrate good ductility after fracture in stress-rupture (e.g. over 11\% ductility after about 14,000 hrs. at $1300^{\circ} \mathrm{F}$, in Table IV).

Iimited elevated temperature tensile data are available after elevated temperature exposure in Table VII. For a sample exposed at $1300^{\circ} \mathrm{F}$ for 835 hours, subsequently fractured at $1300^{\circ} \mathrm{F}$ in short-time tension, Mu phase was detected. The data in Table VII show a slight increase in strength. However, for a slmilarly treated sample at $1400^{\circ} \mathrm{F}$, small losses in strength were noted; Table VII. Even though these data are limited, It is pelt that discussion is warranted to explain these effects. After $1400^{\circ} \mathrm{F}$ exposure, in the samples examined, considerable gamma prime coarsening, as well as precipitation of Mu phase occurred. However, for exposure at $1300^{\circ} \mathrm{F}$, gamma prime coarsening was not as pronounced. Since Mu phase was seen after exposures at both $1300^{\circ} \mathrm{F}$ and $1400^{\circ} \mathrm{F}$ and strength decreases occurred only after $1400^{\circ} \mathrm{F}$ exposure, it is believed that overaging of gamma prime may have a more pronounced effect on weakening this alloy than formation of Mu phase. Furthermore, some unpublished data on Waspaloy indicates that this nickel-base alloy, with a PHACOMP number (or $\mathrm{Nv}_{f}$ ) (10) of 2.20 (and thus, apparently not prone to form any incongruous phases) also suffers a decrease in room temperature tensile strength after exposure at $1400^{\circ} \mathrm{F}$. This further supports the proposal that weakening of Pyromet 860 after $1400^{\circ} \mathrm{F}$ exposure can be attributed primarily to overaging of gamma prime. Additional microstructural studies to verify this are planned. It should be noted that these data were not ava11able when Reference 6 was completed. 
At Room Temperature. The "creep stability" test was originally developed to indicate the effects of creep (or thermal) exposures on the ambient temperature properties of an alloy. Apparently, the designer worries that embrittlement may occur to render his structure susceptible to catastrophic failure; for example, in the case of the re-start of a gas turbine after shut down subsequent to a long run. The usual measure of stability is the room temperature tensile test. The present results establish a portion of the stability range for Pyromet 860 .

The data in Table $V$ for exposures up to 5716 hrs. at $1050^{\circ} \mathrm{F} / 96 \mathrm{ksi}$ definitely indicate that such an exposure has no effect on the stability of this alloy. Conversely, the data for exposures of $37,660 \mathrm{hrs}$. at $1200^{\circ} \mathrm{F} / 50 \mathrm{ksi}, 1124 \mathrm{hrs}$. at $1350^{\circ} \mathrm{F} / 50 \mathrm{ksi}$ and $33,222 \mathrm{hrs}$. at $1400^{\circ} \mathrm{F} / 15 \mathrm{ksi}$ indicate some loss in strength due to these exposures. Certainly, the strain suffered by the samples tested at $1200^{\circ} \mathrm{F} / 50 \mathrm{ks}$ and $1400^{\circ} \mathrm{F} / 15 \mathrm{ksi}$ - due to the application of the stress, had some effect on the extremely low tensile ductility of these samples at room temperature.

A more comprehensive study of the results of elevated temperature exposure on the ambient temperature properties of this alloy can be made by considering the data in Table VII. Tor $1400^{\circ} \mathrm{F}$ exposure, these data show, in general, a progressive weakening and loss in room temperature tensile ductility due to exposures at conditions which overage gamma prime and produce Mu phase. At $1300^{\circ} \mathrm{F}$, a slight improvement in strength is realized and ductility decrease is not nearly as rapid or consistent as occurred at $1400^{\circ} \mathrm{F}$. For both $1300^{\circ} \mathrm{F}$ and $1400^{\circ} \mathrm{F}$ exposures, exposure stress has a pronounced effect on final ambient temperature ductility. Data at $1200^{\circ} \mathrm{F}$ and $1100^{\circ} \mathrm{F}$ are incomplete at this writing, but no instability is expected at these temperatures to very long times. This strength behavior, when considered in light of the structural changes to be discussed below, is not surprising.

Structural Stability:

The primary effects of elevated temperature exposure presented above are related to:

1. Gamma prime coarsening and agglomeration.

2. Carbide and accompanying grain boundary reactions, and

3. Formation of incongruous phases. Since the literature contains numerous data on the first two types of these reactions, for alloys of the Pyromet 860 type, extensive discussion on these will not be given. Most emphasis will be placed on the occurrence of the unknown phase and Mu phase. Even though gamma prime coarsening and agglomeration are not discussed extensively here, their influence on properties cannot be minimized, as has been indicated above.

As can be seen by comparing the various structural electron micrographs in Figures 5 through 16, gamma prime effects are primarily dependent on exposure temperatures. In general, exposures at temperatures up to $1100^{\circ} \mathrm{F}$ did not affect 
gamma prime size or distribution appreciably. At $1200^{\circ} \mathrm{F}$, after 37,660 hours and after higher temperature exposures, coarsening and agglomeration of gamma prime occurs for Pyromet 860. This is especially true at $1400^{\circ} \mathrm{F}$ and above. This result is not unexpected since the aging range for Pyromet 860 is from $1200^{\circ} \mathrm{F}$ to about $1700^{\circ} \mathrm{F}$. Other than $\mathrm{MC}$ type carbides, or $\mathrm{Ti}(\mathrm{C}, \mathrm{O}, \mathrm{N})$, that are products of the melting and solidification on Pyromet 860 , the primary carbide phase of interest in this alloy is $M_{23} \mathrm{C}_{6}$. This is the phase seen in the grain boundaries, for example, in the as-heat-treated samples in Figure 5 . After the various exposures at $1100^{\circ} \mathrm{F}$ and below, very little, if any changes occur. A few areas indicative of grain boundary gamma prime precipitation and/or denudation adjacent to the grain boundaries have been noted. These may be related to a reaction of the type: (8)

$$
\gamma+\mathrm{MC} \rightarrow-m-\mathrm{M}_{23} \mathrm{C}_{6}+\gamma^{\prime}
$$

for gamma prime precipitation near grain boundaries, while the formation of $\mathrm{M}_{23} \mathrm{C}_{6}$ from matrix elements with subsequent increased solubility for Al in the region of grain boundaries can account for a region denuded of gamma prime.

At $1200^{\circ} \mathrm{F}$ and above, definite evidence of $\mathrm{M}_{23} \mathrm{C}_{6}$ growth is noted. That is, after exposures, more areas of nearly continuous grain boundary $\mathrm{M}_{23} \mathrm{C} 6$ as well as areas of agglomerated or blocky $\mathrm{M}_{23} \mathrm{C}_{6}$ are noted than in the as-heat-treated samples. Some of these areas are accompanied by gamma prime agglomeration and others by gamma prime denudation depending upon the mechanism of $\mathrm{M}_{23} \mathrm{C}_{6}$ growth. However, these results are not unexpected and will not be discussed further.

The reaction of primary interest in this work is the formation of Mu phase. Mu is a rhombohedral-hexagonal phase based upon the stolchiometry Co6Mo7. This phase was first designated $M u$ in the Iiterature by Beck, et al. $(12,13)$ In this phase, the Co may be partialiy replaced by $\mathrm{Ni}$ (13) and Mo may be paxtially replaced by Cr. (14). In Pyromet 860, all Mu detected was rich in $\mathrm{Co}, \mathrm{Ni}$ and $\mathrm{Mo}$.

According to Beck, et al (13) Mu is an "electron vacancy phase" (that is, a phase whose occurrence can be predicted by electron vacancy or Nv type calcalations) since its phase boundaries in the systems they studied aligned with lines of constant electron vacancy number. Beck, et al (13) also indicate that $\mathrm{Nv}$ numbers for $\mathrm{Mu}$ are usualiy lower than those for sigma phase. It is interesting to note that Lux and Bollmann (14) auggcst the use of Mu phase as an age hardening phase in Co-Cr-Mo alloys. Alloys produced in their work (14) showed creep-rupture strength and ductility of the same order as the commercial nickel-base alloys Nimonic $80 \mathrm{~A}$ and Nimonic 95.

According to Beattie and Hagel, (15) Mu is a topologically close packed (TCP) phase. TCP phases are characterized (8) by close-packed layers of atoms aligned with octahedral planes of the FCC gamma matrix. Beattie and Hagel (15) indicate that TCP phases prefer the iron-base superalloys over the nickel or 
cobalt base superalloys.

Microstructurally, the Mu phase in Pyromet 860 takes the appearance of platelets. In profuse amounts, angular relationships between the $\mathrm{Mu}$ phase platelets suggest octahedral plane relationships with the matrix as described by Sims. (8). The present studies indicate that the Mu phase platelets nucleate initially in the vicinity of grain boundaries. However, there is no evidence in the present work that $\mathrm{Mu}$ phase nucleation occurs primarily on a carbide such as $\mathrm{M}_{23} \mathrm{C}_{6}$, as has been noted in the literature for sigma phase. An example of this can be seen in the work of woodyatt, Sims and Beattie. (10) Another interesting factor is that limited studies of metallographic sections through fractures of both elevated temperature and room temperature specimens discussed above, show that fracturing does not occur along the $\mathrm{Mu}$ platelets as has been noted in the literature for sigma. Rather, the fractures of Pyromet 860 are primarily intergranular at all temperatures.

Dulis (16) has indicated that Mu phase formation may occur as a result of overaging gamma prime. Initially, it was felt that this may be the case for Pyromet 860 (see Figure. 6d). However, the difference in etching behavior of the gamma prime, Mu and alloy matrix with increasing amounts of Mu indicate that Mu forms from matrix austenite.

The effects of the Mu phase formation on the subsequent mechanical properties of Pyromet 860 have been discussed above. Figure 17 is given as a tentative representation of the kinetics of Mu phase formation in Pyromet 860. It was decided to determine from the literature if other alloys of this type formed $\mathrm{Mu}$. Interest in INCO 901 alloy was paramount since, in a sense, Pyromet 860 is an "up-graded" version of INCO 901 . That is, Pyromet 860 gives improved properties over INCO 901 alloy with no increase in manufacturing difficulty and little increase in cost.

As early as 1959, Beattie (17) in a discussion of work by Clark and Iwanski (18) recognized Mu phase in 901 alloy after exposures of as few as 115 hours at $1350^{\circ} \mathrm{F}$ and somewhat longer times (approximately 10,000 hrs.) at 1200\% $\mathrm{F}$. Eta phase formation, which does not occur in Pyromet 860 due to the presence of 1.25\% Al, occurred in 901 to a greater degree than even Mu phase formation. (18) The Mo enrichment in the Mu phase for Pyromet 860 , indicated in Figure 11 , certainly is in agreement with the data given by Clark and Iwanski (19) for the Mu formed in 901. Also, our X-ray diffraction patterns for Mu in Pyromet 860 agree exactly with the data given by these investigators $(17,18)$ and Beck, et al. (13)

In 1.961, Beattie and Hagel (20) reported detecting $\mathrm{Mu}$ phase In Rene' 41 as well as INCO 901. For Rene' 41, Mu occurred after exposures of $1000 \mathrm{hrs}$ at 1500,1600 and $1700^{\circ} \mathrm{F}$, however, it did not occur after 1000 hrs. at $1400^{\circ} \mathrm{F}$ and $1800^{\circ} \mathrm{F}$. Apparently, $1000 \mathrm{hrs}$. Is too short a time to produce Mu in Rene 41 at $1400^{\circ} \mathrm{F}$, while the solubility limit for Mu in Rene' 41 lies between 1700 and $1800^{\circ} \mathrm{F}$. For INCO 901 , Mu occurred after exposures of $1000 \mathrm{hrs}$. at $1400,1500,160^{\circ}$ and $1700^{\circ} \mathrm{F}$ 
with none detected for similar times at $1300^{\circ} \mathrm{F}$ or $1800^{\circ} \mathrm{F}$. But as noted above, Beattie (17) found Mu in 901 after only 115 hours at $1350^{\circ} \mathrm{F}$. Alloy M-308 formed Mu for $1000 \mathrm{hr}$. exposures from $1300^{\circ} \mathrm{F}$ to $1600^{\circ} \mathrm{F}$. More recently, Collins, et al (7) reported detecting $\mathrm{Mu}$ in INCO 901 , Rene' 41 and AF-21D after exposures of 1500 hrs. In the temperature range $1600-$ $1700^{\circ} \mathrm{F}$. For at least Rene' 41 , stress did not affect Mu forming tendency. These results show that Mu phase does occur in at least two widely used superalloys, INCO 901 and Rene' 41.

For extended exposures at $1100^{\circ} \mathrm{F}$ (2955 hrs. and over), under stress, a previously unreported phase, tentatively indexed to be hexagonal, was noted. This phase is rich in $F e$, Ni, $\mathrm{Cr}$ and Co. This phase was also detected in $1300^{\circ} \mathrm{F}$ and $140^{\circ} \mathrm{F}$ samples for times shorter than those necessary to form Mu. These results imply that this phase is a transition phase, preceding the formation of Mu. This hexagonal phase, at least in the concentration noted in the present work, is not harmful to the room temperature "stability" of Pyromet 860.

Finally, the present results should be considered in relation to $\mathrm{Nv}$ determinations for the heats of interest, all of Which will form Mu under conditions of exposure defined by Figure 17. Sims (8) has indicated that a PHACOMP (or Nv1) number of about 2.3 predicts Mu will form in an alloy, while he gives about 2.5 for sigma. In particular, he indicates that alloys with $6 \%$ or more molybdenum and/or tungsten (such a.s Rene 62, AFs 1753 and Rene' 41) and a nominal amount of iron or cobalt seem to tend toward laves or $\mathrm{Mu}$, while alloys with lower Mo levels (such as U-700, U-500, N-115) tend to be sigma prone. This rule of thumb, however, breaks down at very high cobalt levels. (20) Considering the Nv data for Pyromet 860 in Table VIII in light of this principle, shows that the current results agree with those described by sims. (8)

$\mathrm{NV}_{\mathrm{SS}}$ (or $\mathrm{NV}_{5}$ in Table VIII) for all of these heats ranges from 2.40 to 2.45. Thus, as far as Pyromet 860 is concerned, the Mu cut-off for NVss is below 2.40. Work is in progress at the Carpenter steel Company Research and Development Center to define a chemistry (and corresponding $\mathrm{NV}$ ) for which Mu will not form in a Pyromet 860 base-type alloy.

\section{Conclusions}

1. The phases present in as-heat-treated Pyromet 860 include the solid-solution strengthened matrix, gamma prime, MC or $\mathrm{Ti}(\mathrm{C}, \mathrm{O}, \mathrm{N})$ and $\mathrm{M}_{2} 3^{\mathrm{C}} 6$.

2. After exposures of about 3,000 hours and over at $1100^{\circ} \mathrm{F}$, under stress, or after shorter times at 1200,1300 and $1400^{\circ} \mathrm{F}$, a previous ly unreported phase containing $\mathrm{Fe}, \mathrm{Ni}, \mathrm{Co}$, Mo occurs. This phase, tentatively indexed as having an hexagonal structure, in the quantities obtained, does not affect the subsequent room temperature mechanical properties of this alloy. 3. After approximately $300 \mathrm{hrs}$. at $1400^{\circ} \mathrm{F}, 500 \mathrm{hrs}$. at $1300^{\circ} \mathrm{F}, 37,000$ hrs. at $1200^{\circ} \mathrm{F}$ and possibly longer times at 
$1100^{\circ} \mathrm{F}$, Mu phase, containing Co, Ni and Mo occurs. Formation of this phase has Ifttle apparent effect on the elevated temperature properties of Pyromet 860 to very long times.

4. Exposure of 500 hours at $1300^{\circ} \mathrm{F}$ did not have any significant effect on amblent temperature strength or ductility of Pyromet 860 even though Mu phase was detected. This suggests that $\mathrm{Mu}$ phase may not have any appreciable embrittling effect under such conditions. Extended time at $1300^{\circ} \mathrm{F}$ and above produces eventual overaging of the gamma prime precipitate in Pyromet 860 which may account for weakening after such exposures, and makes difficult the separation of the effects of $\mathrm{Mu}$ phase on the ambient temperature strength properties of this alloy. Exposure stress has a pronounced effect on the final tensile ductility of such specimens. Grain boundary reactions may also have an effect.

5. The unknown hexagonal phase may be a transition phase preceding in time the formation of Mu in Pyromet 860 for any given temperature.

6. The $\mathrm{NV}_{\mathrm{S}}$ cut-off for $\mathrm{Mu}$ phase formation in alloys of the Pyromet 860 type is below 2.40 .

\section{Acknowledgements}

The authors wish to thank the Management of The Carpenter Steel Company for permission to publish these results. Particular thanks are extended to $G$. B. Heydt for his foresight in beginning the long-time creep tests, over four years ago. 


\section{REFERENCES}

1. U.S. Patent 3,183,084, G. B. Heydt and C. R. Whitney, May $11,1965$.

2. Pyromet 860 Data Sheet, The Carpenter Steel Company, Reading, Pa., March, 1968.

3. G. N. Maniar, C. R. Whitney and H. M. James, Microstructure of Pyromet 860 , a Cobalt-Containing Iron/Nickel-Base HeatResistant Alloy, Cobalt, 31, June, 1966, pp. 87-92.

4. Private communication with H. E. Collins, TRW, Cleveland, Ohio.

5. R. R. MacFarlane and C. R. Whitney, Optimizing Heat Treatments for Precipitation Hardening Superalloys, Metal Progress, 91, February, 1967, pp. 75-78.

6. D. R. Muzyka and C. R. Whitney, Short Term Time-Temperature Tests Predict Long Term Test Data for Turbine Alloy, submitted for publication in Metal Progress.

7. H. E. Collins et al, Research on Microstructural Instability in Nickel-Base Superalloys, Contract AF 33(615)-5126, TRW, Inc., Cleveland, Ohio, Interim Engineering Progress Reports 1, October, 1966, 2, January, 1967, 3, April, 1967,4, July, 1967, 5, Óctóber, 1967, 6, January, 1968, 7. April, 1968.

8. C. T. Sims, A Contemporary View of Nickel-Base Superalloys, Journal of Metals, 18, October, 1966, pp. 1119-1130.

9. G. N. Maniar, D. R. Muzyka and C. R. Whitney, unpublished work.

10. L. R. Woodyatt, C. T. Sims and H. J. Beattie, Jr., Prediction of Sigma-Type Phase Occurrence from Compositions in Austenitic Superalloys, Transactions AIME, 236, April, 1966 , pp. 519-526.

11. W. J. Boesch and J. S. Slaney, Preventing Sigma Phase Embrittlement in Nickel Base Superalloys, Metal Progress, 86, July, 1964, pp. 109-112.

12. S. Rideout, W. D. Manly, E. L. Kamen, B. S. Lement and P. A. Beck, Intermediate Phases in Ternary Alloy Systems of Transition Elements, Transactions AIME, 191, October, 1951, pp. 872-876. 
References: (continued)

13. D. K. Das, S. P. Rideout and P. A. Beck, Intermediate Phases in the Mo-Fe-Co, Mo-Fe-Ni and Mo-Ni-Co Ternary Systems, Transactions AIME, 194, October, 1952, pp. 10711075.

14. B. Lux and W. Bollmann, Precipitation Hardening of Co-Base Alloys by Means of an Intermetallic Co-Mo Phase, Cobalt, 11, June, 1961, pp. 1-17.

15. H. J. Beattie, Jr. and W. C. Hagel, Compositional Control of Phases Precipitating in Complex Austenitic Alloys, Transactions AIME, 233, February, 1965, pp. 277-287.

16. E. J. Dulis, Age-Hardening Austenitic Stainless Steels, Metallurgical Developments in High-Alloy Steels, ISI Special Report No. 86, 1964, pp. 162-183.

17. H. J. Beattie, Jr., Discussion of Reference (18), Transactions AIME, 218, April, 1960, pp. 368-369.

18. C. C. Clark and J. S. Iwanski, Phase Changes in Precipitation Hardening Nickel-Chromium-Iron Alloys during Prolonged Heating, Transactions AIME, 215, August, 1959, pp. 648-651.

19. C. C. Clark and J. S. Iwanski, Reply to Reference (17), Transactions AIME, 218, April, 1960, p. 369.

20. H. J. Beattie, Jr. and W. C. Hagel, Intragranular Precipitation of Intermetalic Compounds in Complex Austenitic Alloys, Transactions AIME, 221, February, 1961, pp. 2835. 
TABLE I

CHEMICAL ANALYSES OF PYROMET 860 HEATS

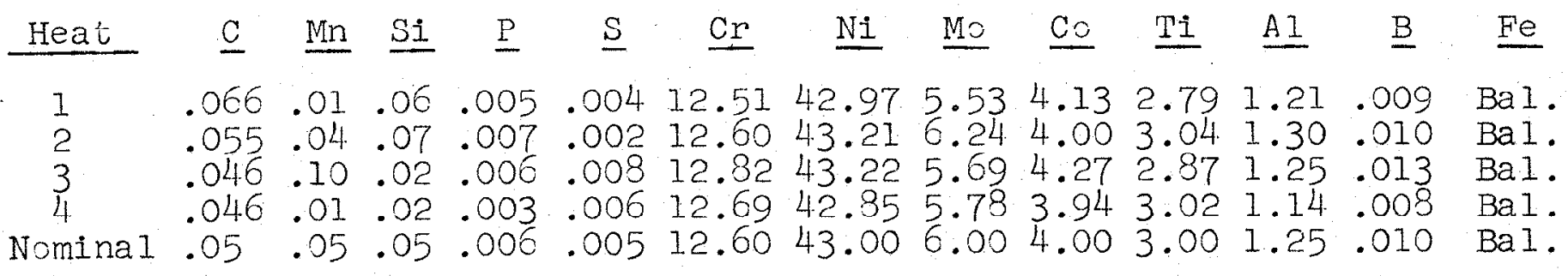

TABLE II

HEAT TREATMENT SEQUENCES FOR PYROMET 860 ALLOY

\begin{tabular}{|c|c|c|}
\hline Code & Solution Treat & Age \\
\hline A & $2000^{\circ} \mathrm{F} / 2 \mathrm{hrs} / \mathrm{WQ}$ & $1525^{\circ} \mathrm{F} / 2 \mathrm{hrs} / \mathrm{AC}+1400^{\circ} \mathrm{F} / 24 \mathrm{hrs} / \mathrm{AC}$ \\
\hline B & $2000^{\circ} \mathrm{F} / 2 \mathrm{hrs} / \mathrm{WQ}$ & Same as A, plus $1200^{\circ} \mathrm{F} / 16 \mathrm{hrs} / \mathrm{AC}$ \\
\hline C & $2000^{\circ} \mathrm{F} / 2 \mathrm{hrs} / \mathrm{WQ}$ & $1425^{\circ} \mathrm{F} / 24 \mathrm{hrs} / \mathrm{AC}+1250^{\circ} \mathrm{F} / 24 \mathrm{hrs} / \mathrm{AC}$ \\
\hline 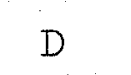 & $2000^{\circ} \mathrm{F} / 2 \mathrm{hrs} / \mathrm{WQ}$ & $1525^{\circ} \mathrm{F} / 16 \mathrm{hrs} / \mathrm{cool} 35^{\circ} \mathrm{F} / \mathrm{hr}$ to $1250^{\circ} \mathrm{F} / 24 \mathrm{hrs} / \mathrm{AC}$ \\
\hline
\end{tabular}


Page 10

TABLE III

STRESS-RUPTURE PROPERTIES OF PYROMET 860

FOR VARIOUS HEAT TREATED CONDITIONS

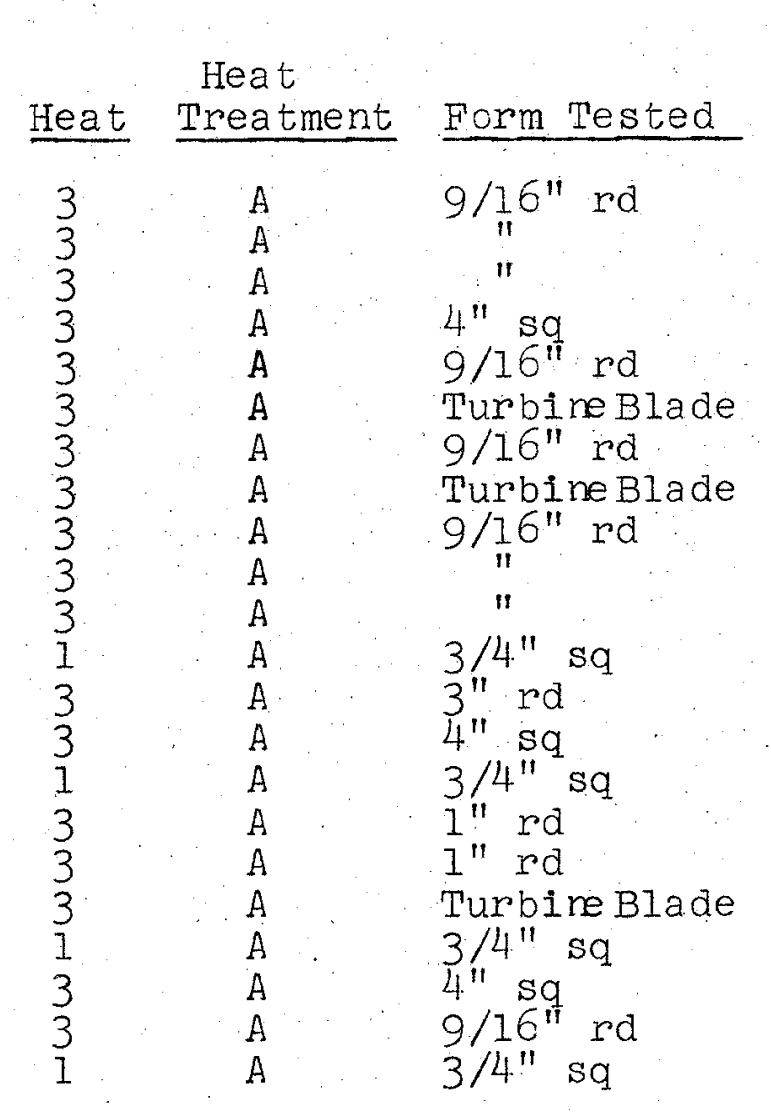

\begin{tabular}{|c|c|}
\hline \multicolumn{2}{|c|}{ Test } \\
\hline $\begin{array}{l}\text { Temp. } \\
\left({ }^{\circ} \mathrm{F}\right)\end{array}$ & $\begin{array}{l}\text { Stress } \\
\text { (ksi) }\end{array}$ \\
\hline $\begin{array}{l}850 \\
1000 \\
" 1\end{array}$ & $\begin{array}{l}165 \\
175 \\
130\end{array}$ \\
\hline 1050 & 130 \\
\hline 1100 & 150 \\
\hline$"$ & 120 \\
\hline " & 105 \\
\hline 11 & 100 \\
\hline 1200 & 120 \\
\hline "1 & 115 \\
\hline$" 1$ & 100 \\
\hline$"$ & \\
\hline 11 & $"$ \\
\hline$"$ & $"$ \\
\hline " & 95 \\
\hline$"$ & $\pi$ \\
\hline$"$ & 11 \\
\hline " & i" \\
\hline " & 90 \\
\hline 790 & \\
\hline 1300 & $\begin{array}{r}105 \\
75\end{array}$ \\
\hline
\end{tabular}

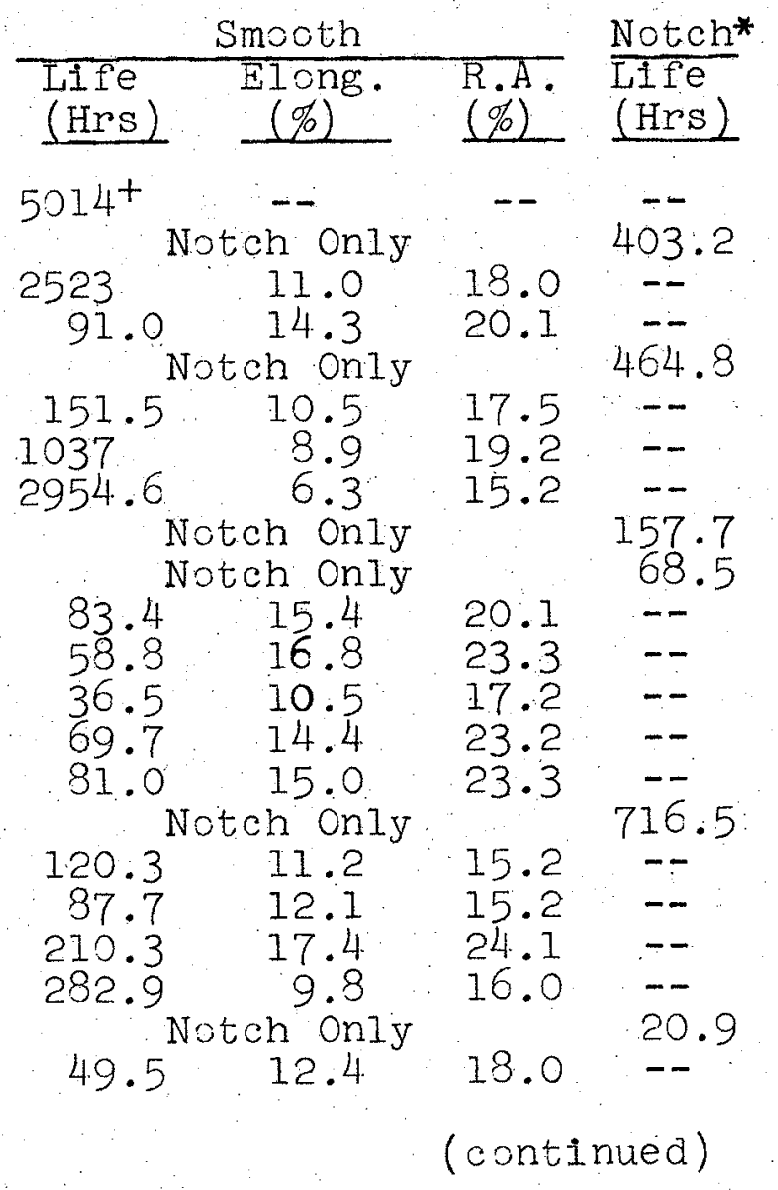


TABLE III (CONTINUED)

STRESS-RUPTURE PROPERTIES OF PYROMET 860

FOR VARIOUS HEAT TREATED CONDITIONS

Heat

Heat Treatment Form Tested

1
1
3
3
3
1
2
1
2
1
2
2
2
2
3
3
3
3
3
3
3
3
3
3
3
3

$A$
$A$
$A$
$A$
$A$
$A$
$A$
$A$
$A$
$A$
$A$
$A$
$A$
$A$
$A$
$B$
$B$
$B$
$B$
$C$
$C$
$C$
$C$
$C$
$C$
$C$
$C$
$C$
$C$

$3 / 4^{\prime \prime} \cdot \mathrm{sq}$

Turbine Blade

$9 / 1^{\prime \prime}$ ra

$3 / 4^{\prime \prime} \mathrm{sq}$

II

II.

"

"I

II

$" 1$

$9 / 1^{\prime \prime} 6^{\prime \prime}$ nd

"

$4^{\prime \prime} \mathrm{sq}$

Turbine Blade

9/16" rd

$3^{\prime \prime} \mathrm{rd}$

4" sq

I" rd

Turbine Blade

\begin{tabular}{|c|c|}
\hline \multicolumn{2}{|c|}{ Test } \\
\hline $\begin{array}{l}\text { Temp. } \\
\text { (oF) }\end{array}$ & $\begin{array}{l}\text { Stress } \\
\text { (ksi) }\end{array}$ \\
\hline 1300 & $\begin{array}{l}70 \\
65\end{array}$ \\
\hline 1350 & 50 \\
\hline $\begin{array}{c}1400 \\
" 1\end{array}$ & $\begin{array}{l}65 \\
60\end{array}$ \\
\hline$" 1$ & 47 \\
\hline$" 1$ & 47 \\
\hline$n$ & 42 \\
\hline 11 & 42 \\
\hline$" 1$ & 39 \\
\hline$"$ & 39 \\
\hline 1500 & $\begin{array}{l}35 \\
30\end{array}$ \\
\hline$"$ & 25 \\
\hline 850 & 165 \\
\hline 1000 & 130 \\
\hline 1100 & 105 \\
\hline 1050 & 130 \\
\hline 1100 & 120 \\
\hline 11 & 100 \\
\hline 1200 & 100 \\
\hline$" 1$ & 11 \\
\hline$" 1$ & 95 \\
\hline$" 1$ & 11 \\
\hline 11 & 11 \\
\hline
\end{tabular}

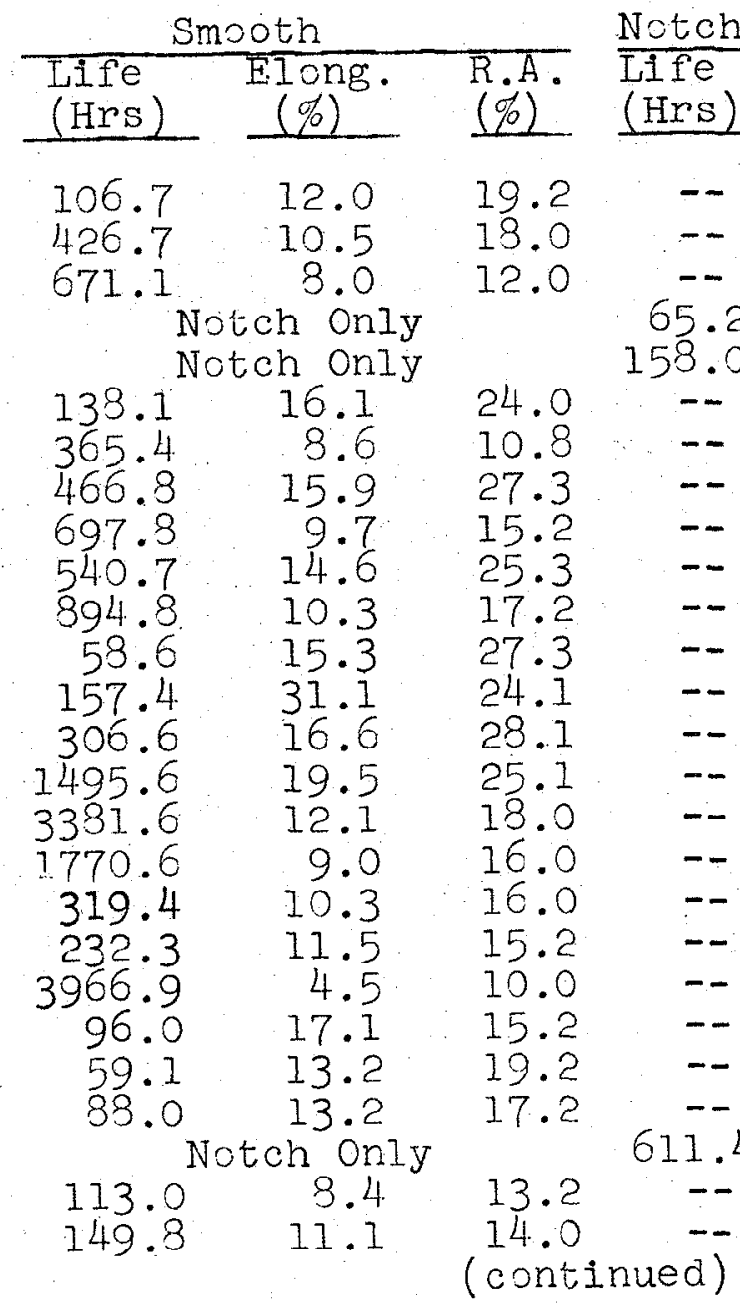


Page 3 of

TABLE III (CONTINUED)

STRESS-RUPTURE PROPERTIES OF PYRONET 860

FOR VARIOUS HEAT TREATED CONDITIONS

Heat

Heat Treatment Form Tested

3
3
3
3
3
3
4
4
4
3
3
4
4
4
4
4
3
3
3
3

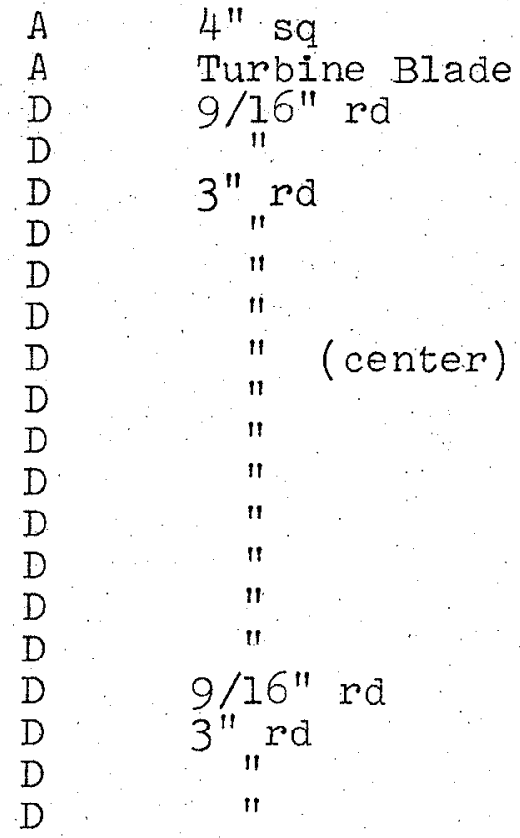

\begin{tabular}{cc}
\multicolumn{2}{c}{ Test } \\
$\begin{array}{c}\text { Temp } \\
\text { ( } \mathrm{F})\end{array}$ & $\begin{array}{c}\text { Stress } \\
\text { (ksi) }\end{array}$ \\
\hline 1200 & 90 \\
1350 & 50 \\
1000 & 140 \\
1050 & 125 \\
11 & 120 \\
11 & 11 \\
11 & $" 11$ \\
11 & 11 \\
11 & 110 \\
11 & 100 \\
11 & 96 \\
11 & 11 \\
$" 1$ & 11 \\
11 & 11 \\
11 & 11 \\
11 & 90 \\
1100 & 110 \\
11 & 70 \\
1200 & 90 \\
1300 & 70
\end{tabular}

\begin{tabular}{|c|c|}
\hline \multicolumn{2}{|c|}{ Smooth } \\
\hline $\begin{array}{l}\text { Life } \\
(\operatorname{Hrs})\end{array}$ & $\begin{array}{l}\text { E1ong. } \\
(\%)\end{array}$ \\
\hline 402.4 & 9.0 \\
\hline 1124.3 & 10.8 \\
\hline $202 \cdot 3$ & 16.7 \\
\hline 103.4 & 10.1 \\
\hline $\begin{array}{l}212.0 \\
245.2\end{array}$ & 8.5 \\
\hline 265.4 & 18.5 \\
\hline 403.7 & 15.1 \\
\hline 165.9 & 22.3 \\
\hline 770.0 & 19.4 \\
\hline 4393.7 & $\begin{array}{l}12.3 \\
23.9\end{array}$ \\
\hline 4709.8 & 27.2 \\
\hline 2737.4 & 24.2 \\
\hline Notch & $\left.K_{t}=4.6\right)$ \\
\hline Notch & $\left(K_{t}=4.6\right)$ \\
\hline 141.8 & 18.7 \\
\hline 117.9 & $20 \cdot 5$ \\
\hline $\begin{array}{l}65.1 \\
49.1\end{array}$ & $\begin{array}{l}16.3 \\
15.3\end{array}$ \\
\hline
\end{tabular}

$\frac{\text { Notch* }}{\text { IIfe }}$

(Hrs)

(\%)

14.0 -

13.2

25.3

13.2

24.6

22.0

25.3

24.0

28.1

22.6

20.1

27.0

28.5

28.0

Notch
Notch $\left(\begin{array}{l}K_{t}=4.6 \\ K_{t}=4.6\end{array}\right)$

141.8

(3)

30.9

28.0

$22: 0$

26.0

+Test Discontinued.

${ }^{*} \mathrm{~K}_{\mathrm{t}}=3.8$ except where otherwise indicated. 
TABLE IV

LONG-TIME CREEP DATA FOR PYROMET 860 ALLOY

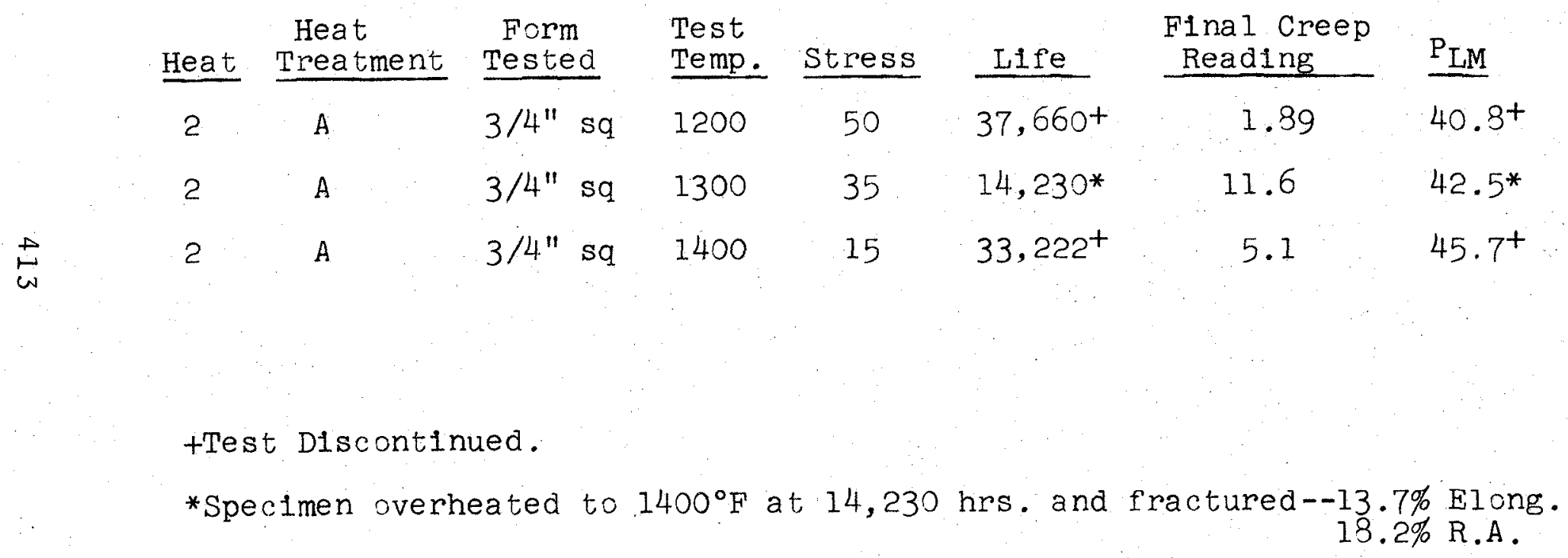


TABLE $\underline{V}$

CREEP/RUPTURE STABILITY TESTS ON PYROMET 360 ALLOY

Form
Treatment Tested Temp. Stress Time Def. Kt 3.8 .02\% YS .2\% YS UTS Elong.

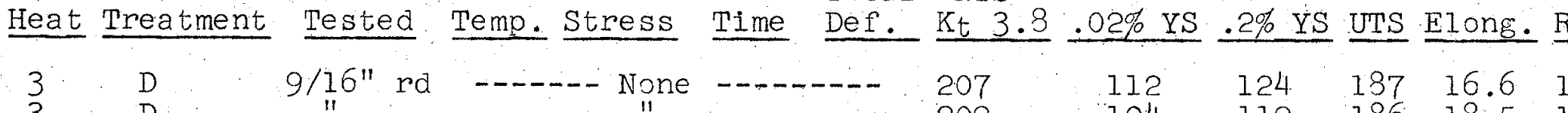

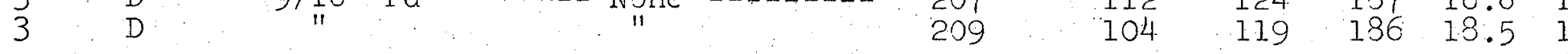

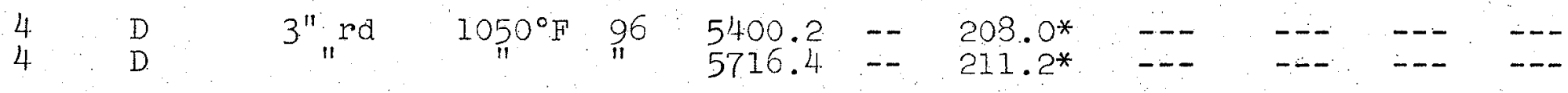

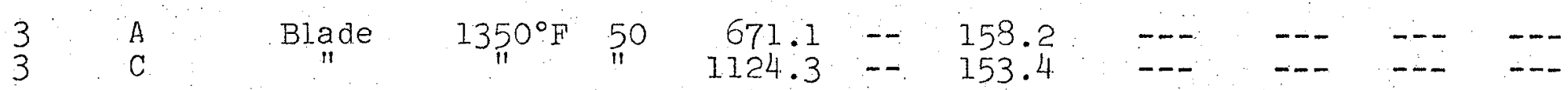

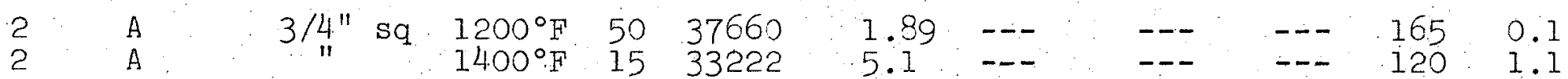

$*_{K_{t}=4.6}$ 
TABLE VI

\section{"d" SPACINGS OF A PHASE* SEEN IN PYROMET 860 \\ COMPARED WITH HEXAGONAL NI3TI}

$\begin{array}{llll}\mathrm{d} & \mathrm{I} & \mathrm{d} & \mathrm{I} \\ 3.10 & \text { VW } & & \\ 2.58 & \mathrm{M} & 2.23 & \mathrm{MW} \\ & & 2.154 & \mathrm{~S} \\ 2.12 & \mathrm{~S} & & \\ 1.99 & \mathrm{~S} & 1.962 & \mathrm{VS} \\ 1.83 & \mathrm{M} & 1.738 & \mathrm{M} \\ 1.56 & \mathrm{~W} & 1.523 & \mathrm{~W} \\ 1.40 & \mathrm{~W} & & \\ 1.34 & \mathrm{M} & 1.334 & \mathrm{MW} \\ 1.28 & \mathrm{M} & 1.279 & \mathrm{MW} \\ 1.19 & \mathrm{M} & 1.179 & \mathrm{~S}\end{array}$

* Tentatively indexed as an hexagonal phase. 


\section{TABLE VII}

STABILITY TESTS ON PYROMET 860 SPECIMENS EXPOSED AT $1100^{\circ} \mathrm{F}-1400^{\circ} \mathrm{F}$, WITH AND WITHOUT STRESS HEAT 3, 9/16" ROUND BAR STOCK, HEAT TREATMENT "A"

(a) Elevated Temperature "Stability Tests"

$\frac{\text { Exposure }}{\text { Time New }} \frac{\text { Nemp. }}{\text { Tems }}$

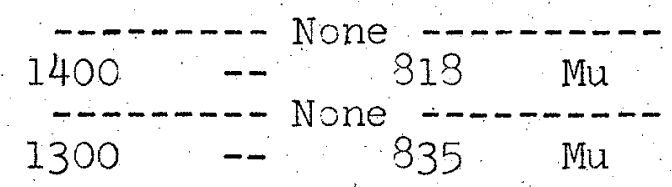

(b) Room Temperature "Stability Tests"

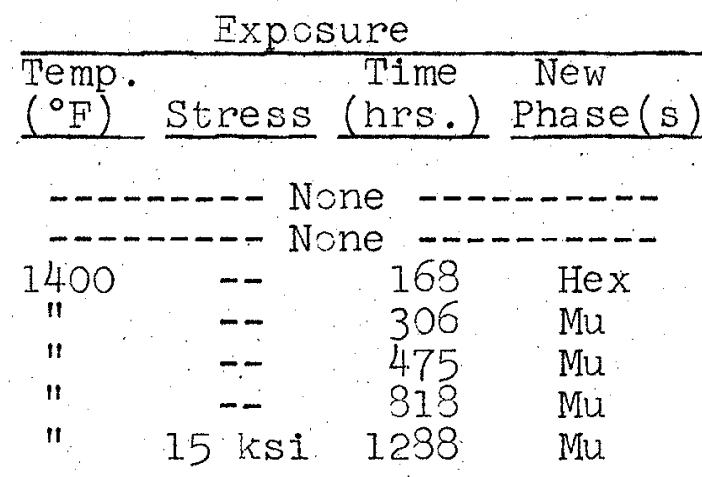

Tensile Properties

\begin{tabular}{|c|c|c|c|c|c|}
\hline $\begin{array}{l}\text { Temp } \\
(\mathrm{O} F)\end{array}$ & $.02 \%$ & $.2 \%$ & U.I & EI & R.f \\
\hline $\begin{array}{l}1400 \\
1400 \\
1300 \\
1300\end{array}$ & $\begin{array}{r}89 \\
63 \\
100 \\
100\end{array}$ & $\begin{array}{r}108 \\
85 \\
118 \\
123\end{array}$ & $\begin{array}{l}117 \\
102 \\
142 \\
148\end{array}$ & $\begin{array}{l}17.2 \\
30.2 \\
16.7 \\
21.7\end{array}$ & $\begin{array}{l}37.3 \\
25.0 \\
28.4\end{array}$ \\
\hline
\end{tabular}


TABIE VII (CONIINUED)

STABILITY TESTS ON PYRONET 860 SPECIMENS EXPOSED AT $1100^{\circ} \mathrm{F}-1400^{\circ} \mathrm{F}$, WITH AND WITHOUT STRE:SS

HEAT 3, 9/16" ROUND BAR STOCK, HEAT TREATMENT "A"

(b) Room Temperature "Stability Tests"

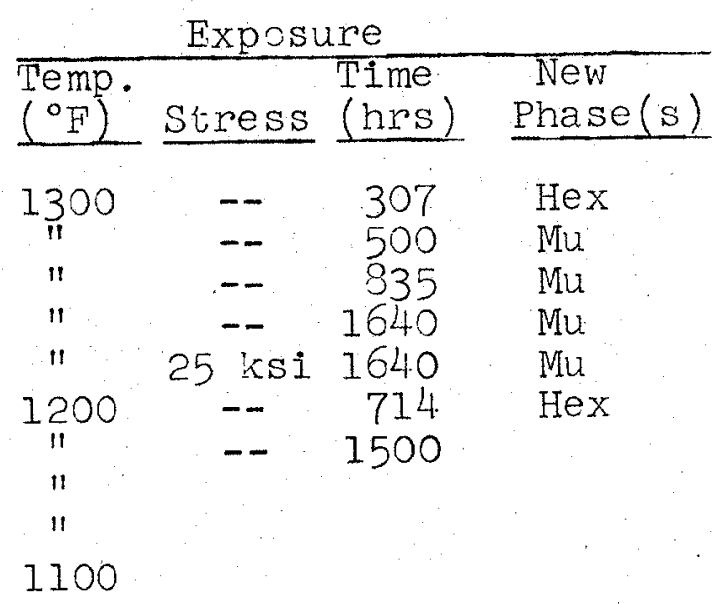

$70^{\circ} \mathrm{F}$ Tensile Properties $.02 \%$ YS .2\% YS U.T.S. Elong. R.A.

$\begin{array}{lllll}111 & 123 & 192 & 20.0 & 19.6\end{array}$

$\begin{array}{lllll}113 & 125 & 189 & 17.3 & 16.7\end{array}$

$\begin{array}{lllll}106 & 121 & 180 & 11.5 & 10.8\end{array}$

$\begin{array}{lllll}113 & 125 & 192 & 16.1 & 15.2\end{array}$

$\begin{array}{lllll}109 & 121 & 176 & 7.3 & 11.0\end{array}$

$\begin{array}{llllll}113 & 126 & 191 & 19.1 & 20.2\end{array}$

$\begin{array}{lllll}114 & 126 & 192 & 17.6 & 20.2\end{array}$ 


\section{TABLE VIII}

$N_{V}$ NUMBERS* FOR VARIOUS PYROMET 860 HEATS (CORRESPONDING CHEMICAL ANALYSES GIVEN IN TABLE I)

\begin{tabular}{|c|c|c|c|c|c|c|c|c|c|c|}
\hline at & v1 & $\mathrm{Nv}_{2}$ & $\mathrm{Nv}_{3}$ & $\mathrm{v}_{4}$ & $v_{5}$ & $\mathrm{Iv}_{6}$ & $\mathrm{~N}_{7}$ & v8 & 9 & vio \\
\hline 1 & .44 & 2.47 & 2.33 & .36 & 0 & 3 & 2.54 & 2.56 & .55 & .59 \\
\hline 2 & .50 & 2.52 & 2.38 & .40 & .45 & 7 & 2.60 & 2.63 & .6 & 2.65 \\
\hline 3 & +0 & 2.49 & 2.35 & .38 & 2 & $c \cdot$ & 2.57 & • & אל & \\
\hline 4 & 47 & 2.50 & .36 & .38 & 3 & 2.45. & 2.58 & 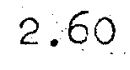 & 2.60 & \\
\hline minal & .48 & 50 & 37 & .39 & & & & & & \\
\hline
\end{tabular}

*Ail $N_{V}$ calculated by TRW according to procedures outlined in reference (7). Nv1 = PHACOMP due to Woodyatt, Sims and Beattie(10) $\mathrm{Nv} 2=$ Procedure due to Boesch and Slaney(II) $\mathrm{NV}_{5}=\mathrm{NV}_{\text {SS }}$ 

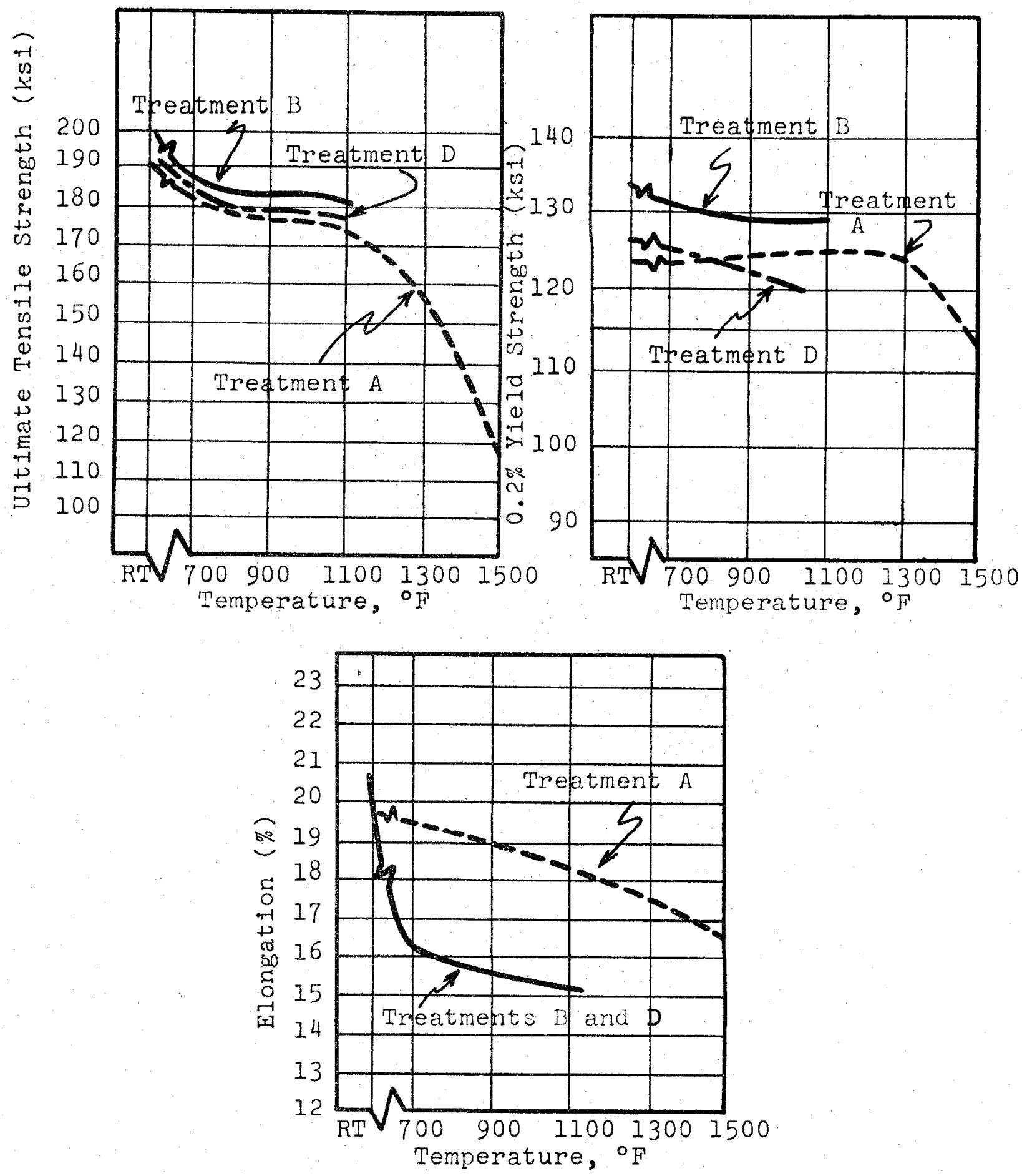

Fig. 1 EFFECT OF HEAT TREATMENT ON THE TENSILE PROPERTIES OF PYROMET 860 ALLOY. 


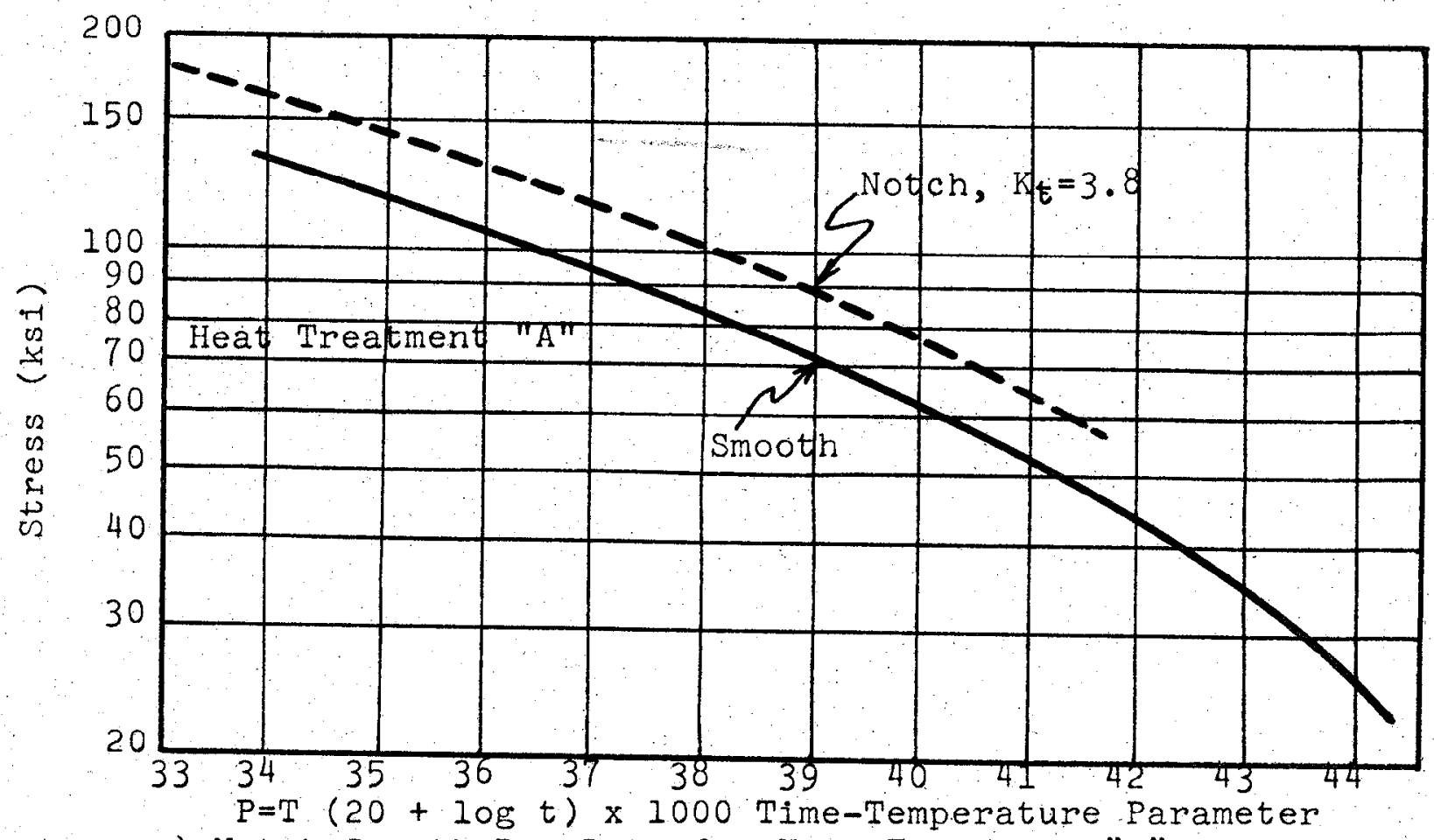

a) Notch-Smooth Bar Data for. Heat Treatment "A"

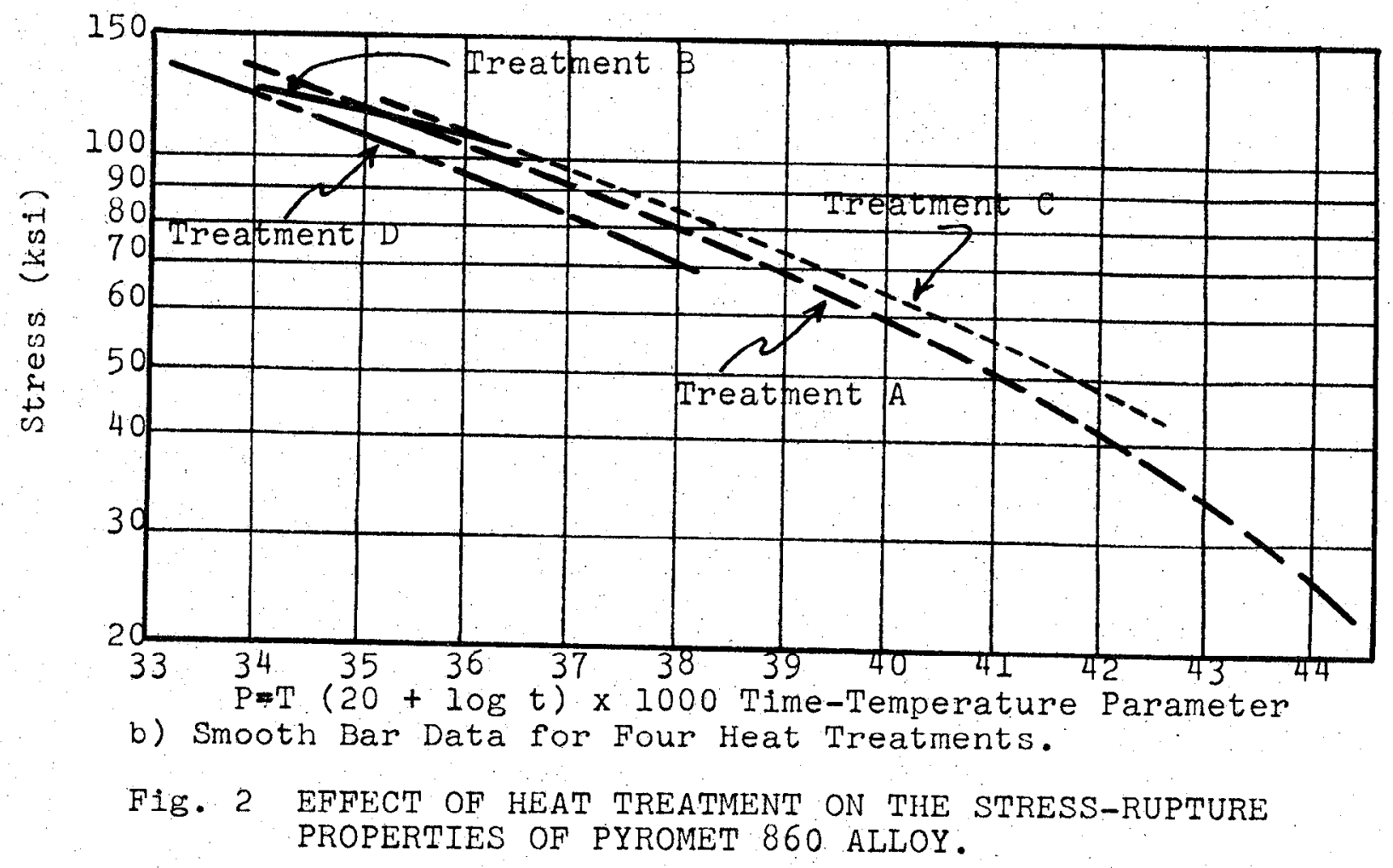




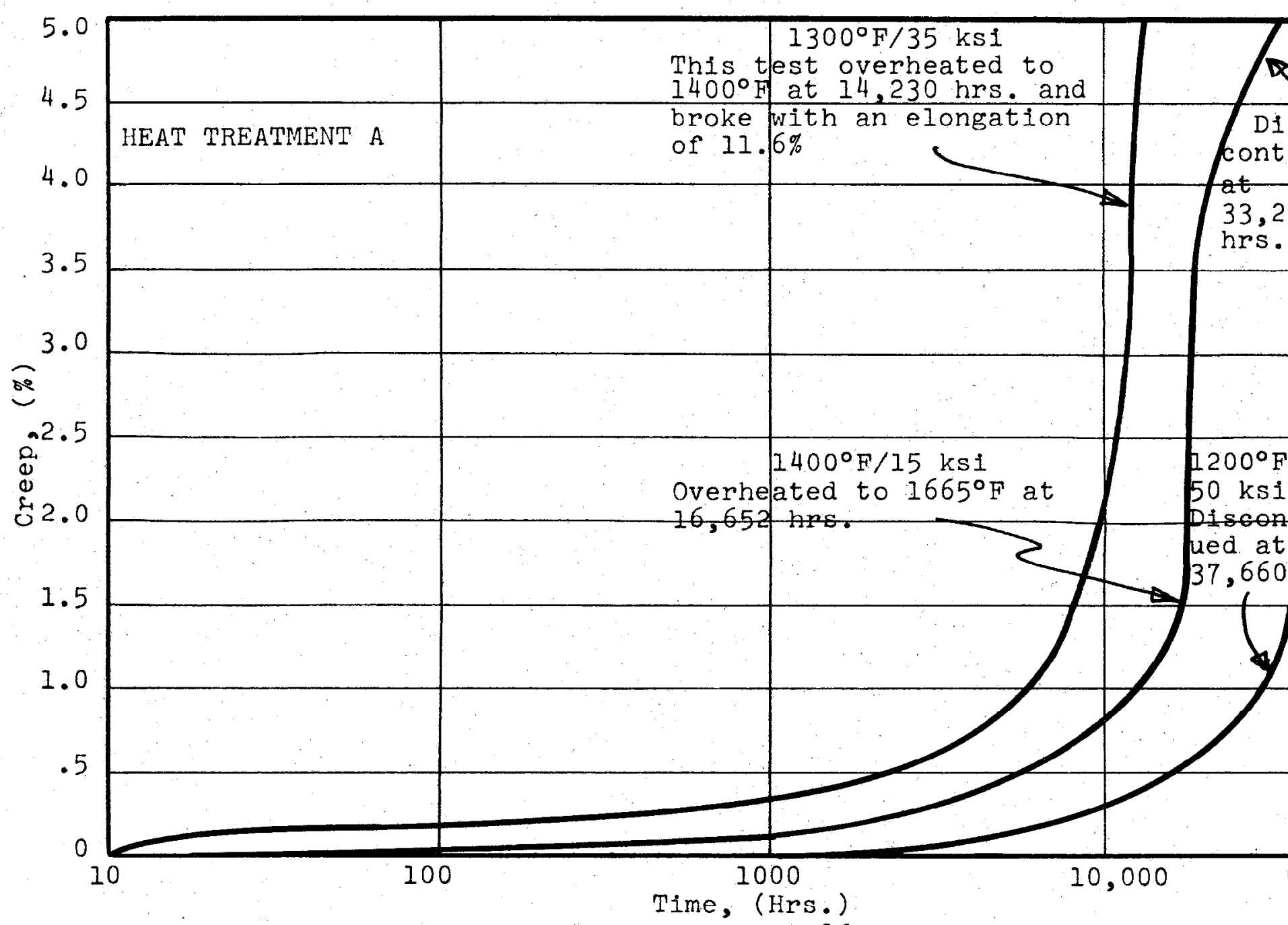

Fig. 3 LONG-TIME CREEP CURVES FOR PYROMET 860 ALLOY. 


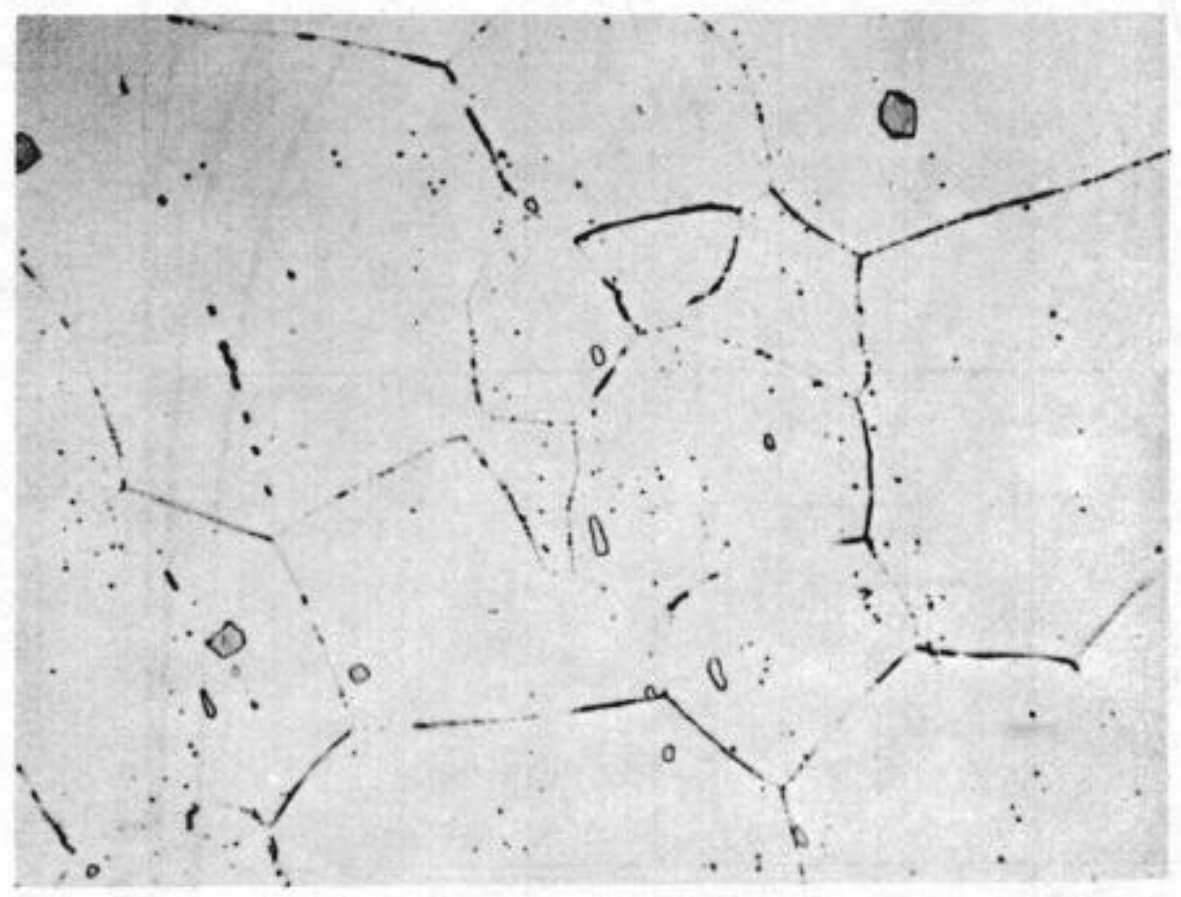

F1gure 4. TYPICAL, AS HEAT-TREATED OPTICAL MICROSTRUCTURE OF PYROMET 860 ALLOY. Heat Treatment: C Heat: 3 Magnification: 500x Etchant: Glyceregla 


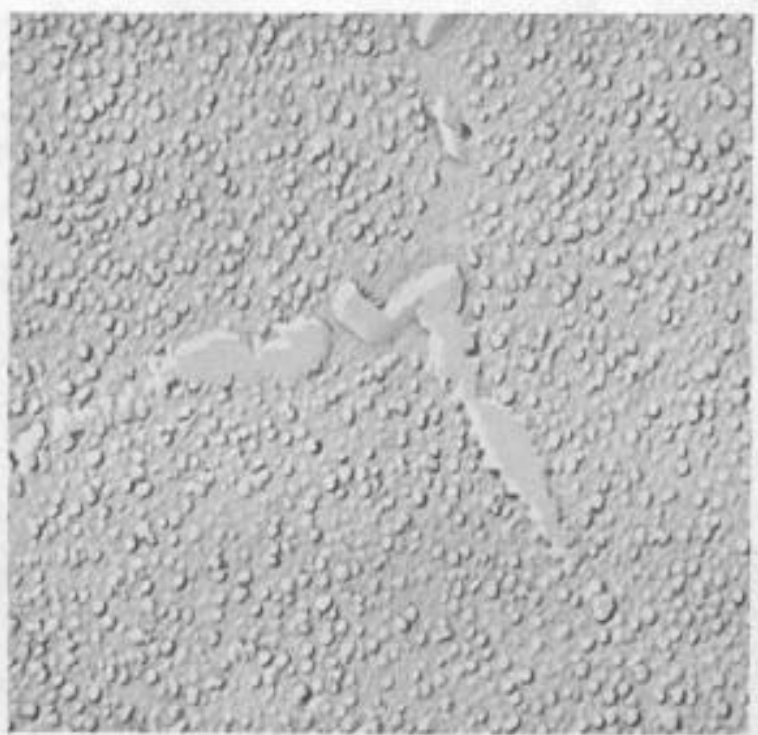

(a)

Heat Treatment $A$, Heat 2

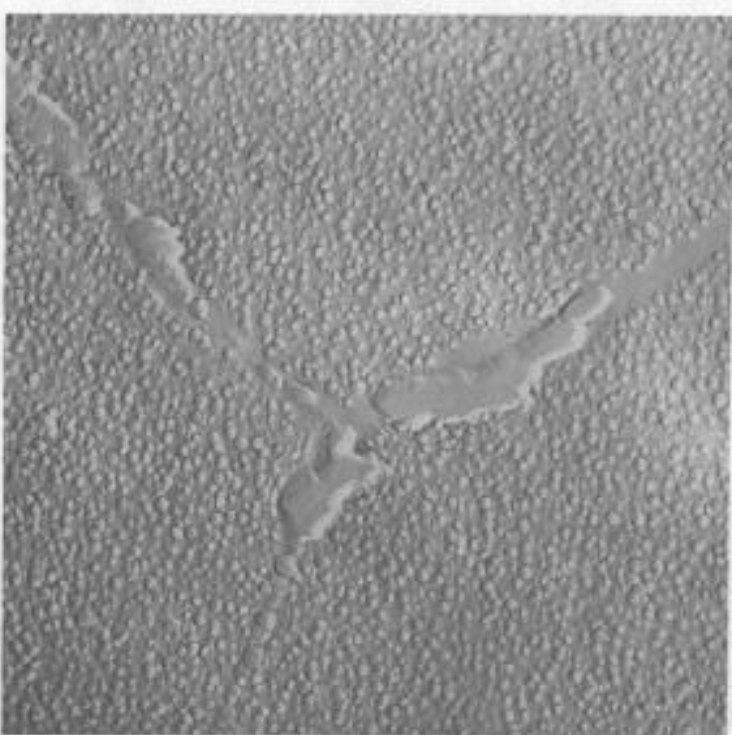

(b)

Heat Treatment B, Heat 3

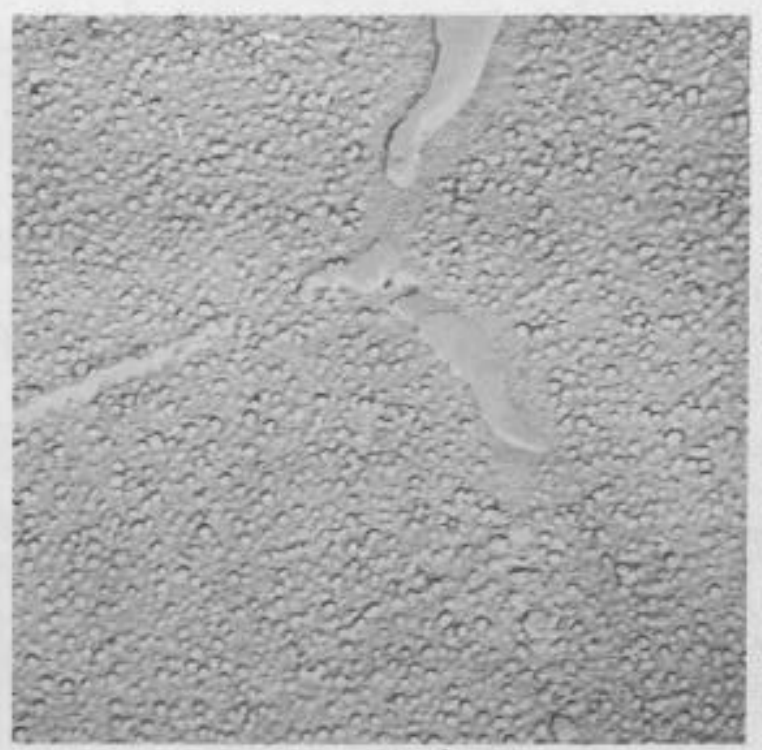

(c)

Heat Treatment $c$, Heat 3

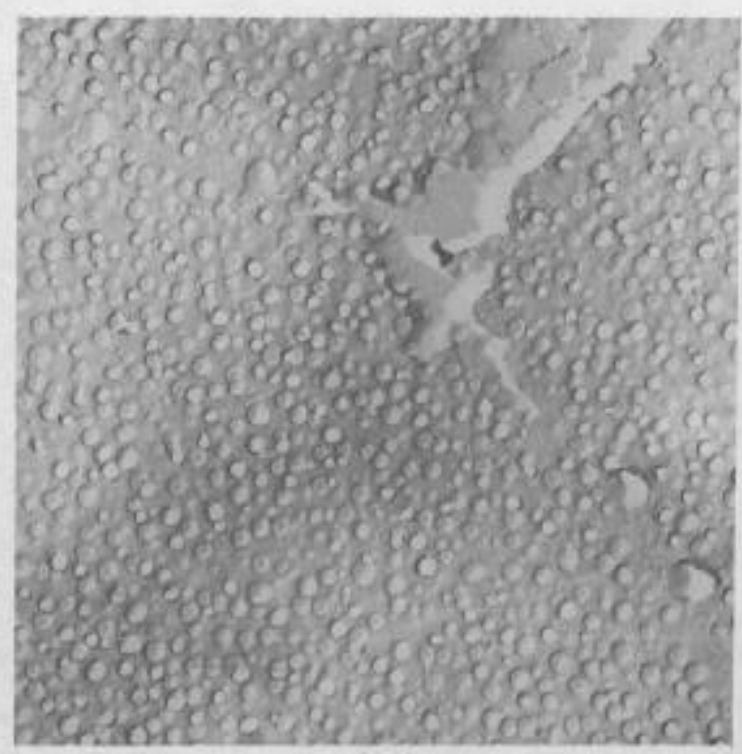

(d)

Heat Treatment $D$, Heat 4

F1gure 5. STRUCTURAL REPLICA ELECTRON MICROSTRUCTURE OF AS-HEAT-TREATED PYROMET 960 ALLOY.

Heat Treatment: as indicated

Heat: as indicated

Magnif1cat1on: 25, 000X

Etchant: "G" 


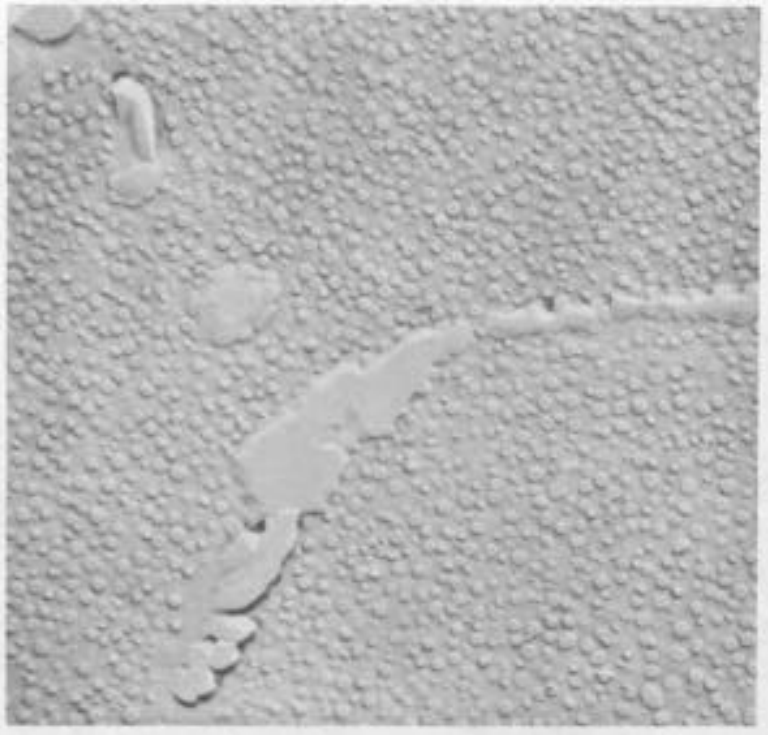

(a)

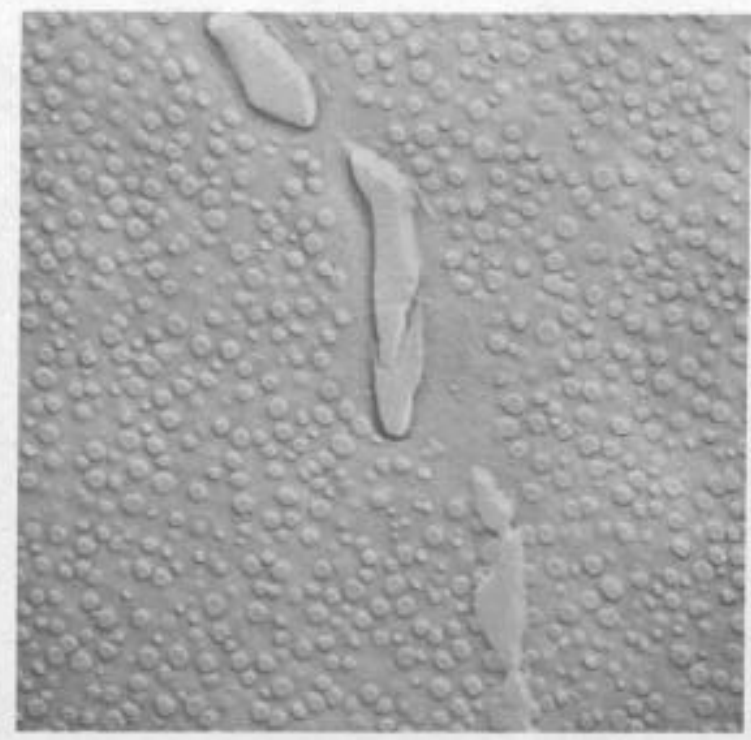

(b)

25, $000 \mathrm{x}$

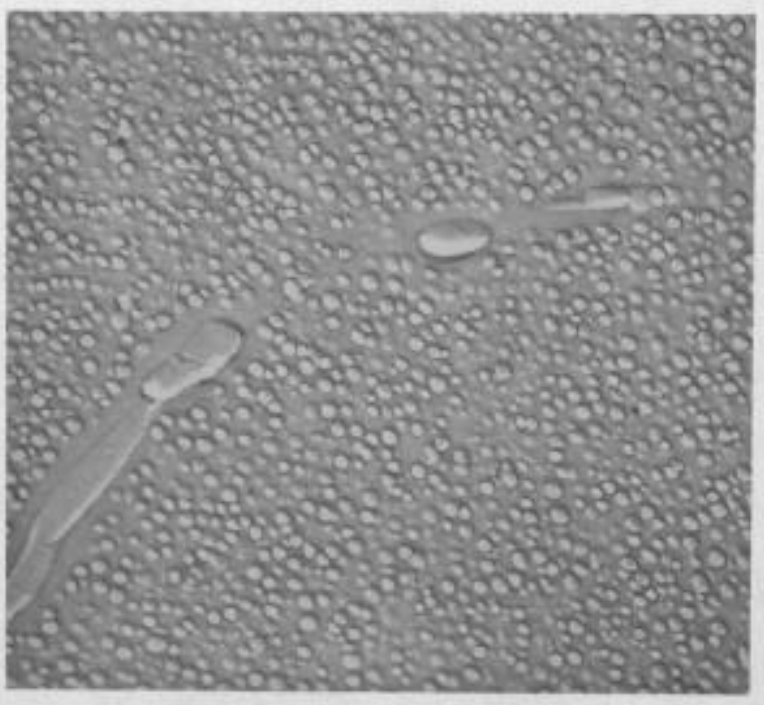

(c)
$17,500 \times$
4709 Hrs.

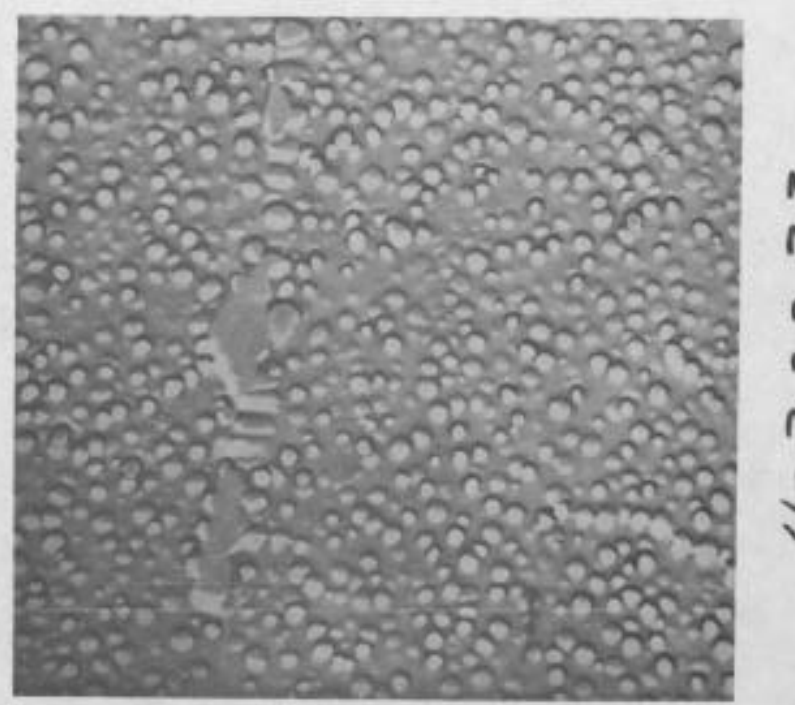

(d)

25, $000 \mathrm{x}$

F1gure 6. ELECTRON MICROSTRUCTURE OF PYROMET 860 ALLOY AFTER EXPOSURE AT $1050^{\circ} \mathrm{F}$.

Heat Treatment: D

Heat: 4

Magnification: as indicated

Etchant: "G" 


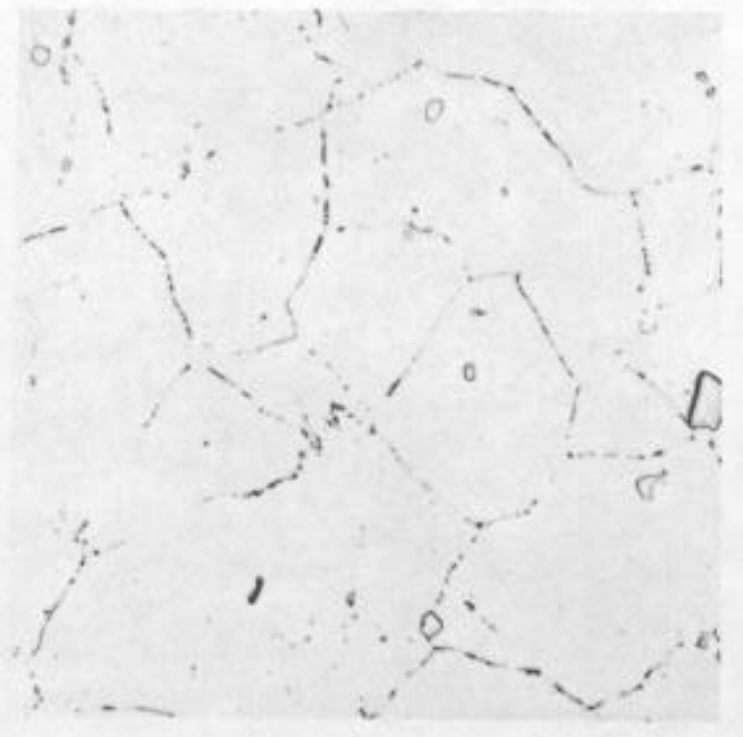

(a) $500 x$

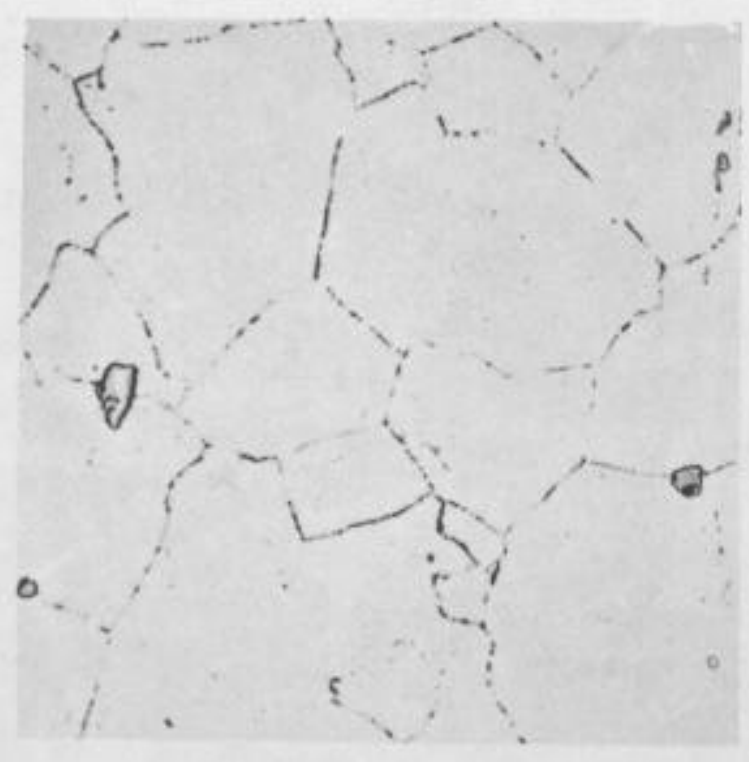
(c)
$1771 \mathrm{Hrs}$.

1037 Hrs.

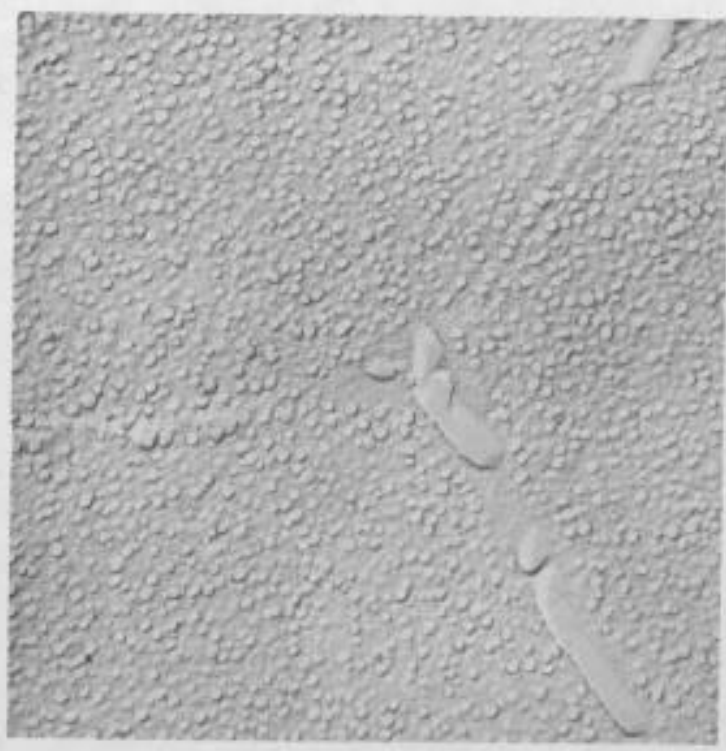

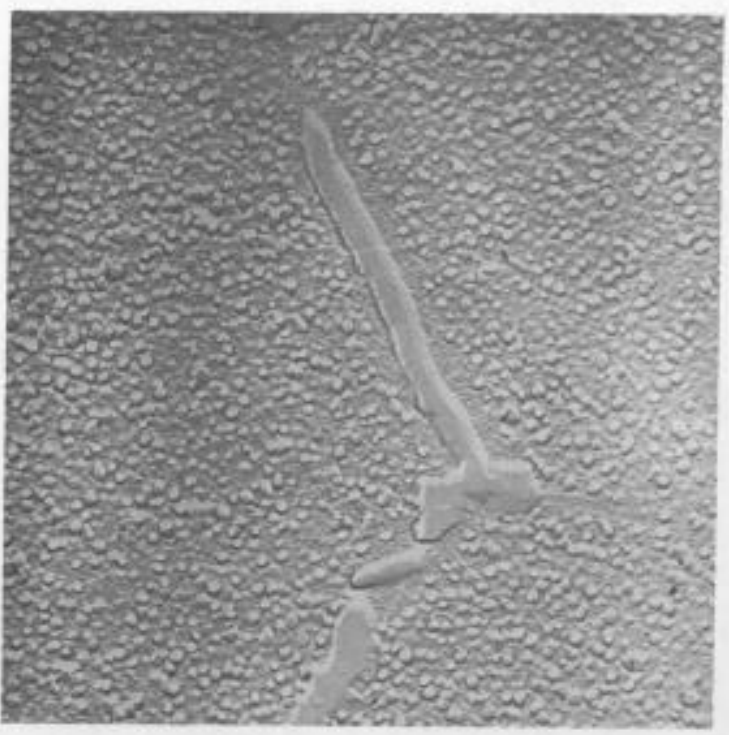

(b)

$25,000 x$

F1gure 7. MICROSTRUCTURE OF PYROMET 860 ALLOY AFTER EXPOSURE AT $1100^{\circ} \mathrm{F}$.

Heat Treatment: $1037 \mathrm{Hrs}$. - A $1771 \mathrm{Hrs}$. - B

Heat: 3

Magnification: as indicated

Etchant: L1ght Microstructure - Glyceregia Electron Microstructure - "G" 


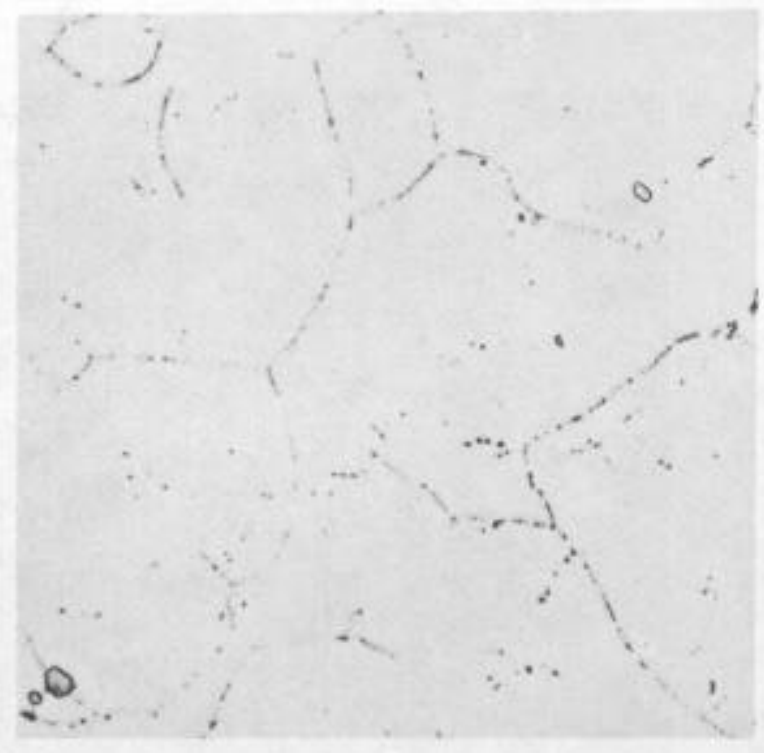

(a)

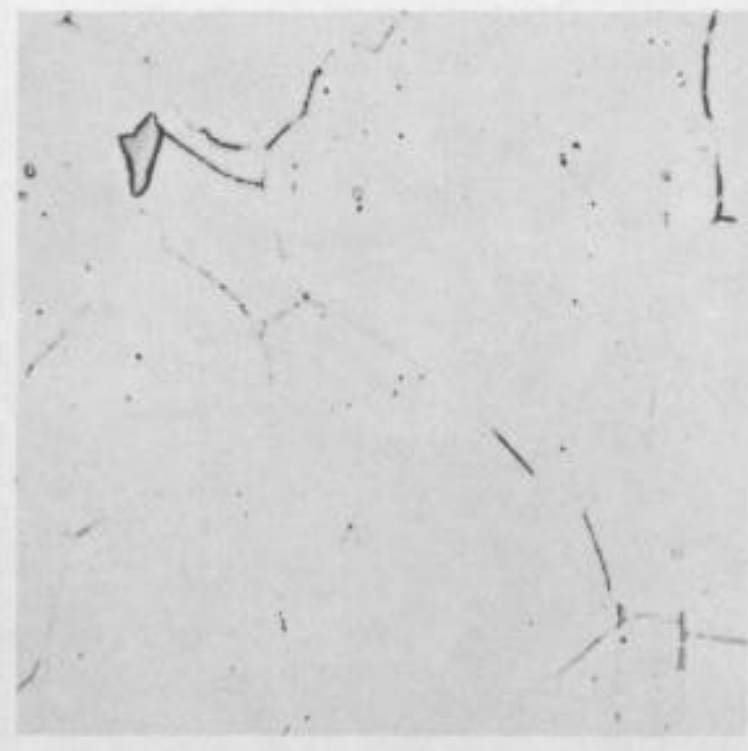

(c)

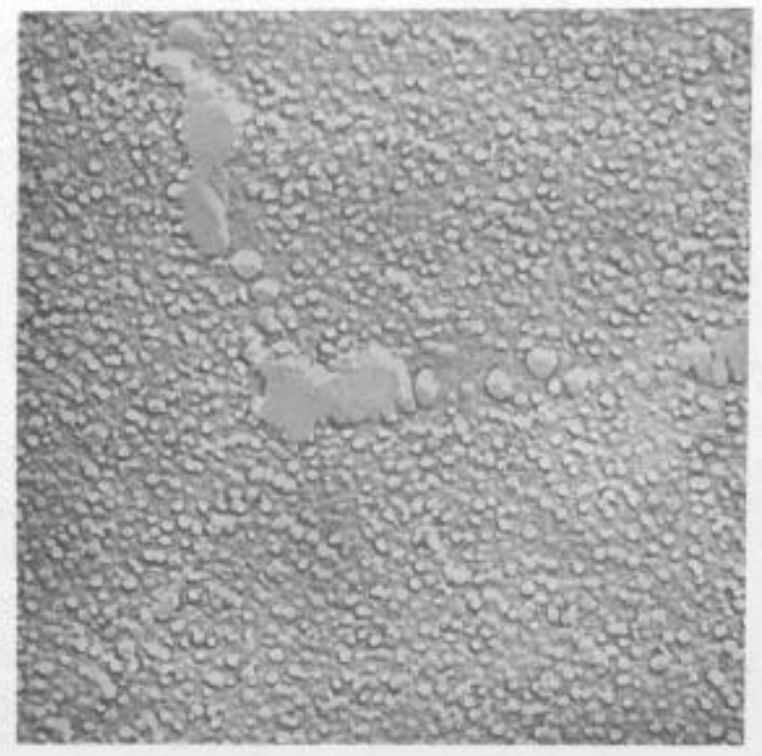

2955 Hrs.

(b)

$25,000 x$

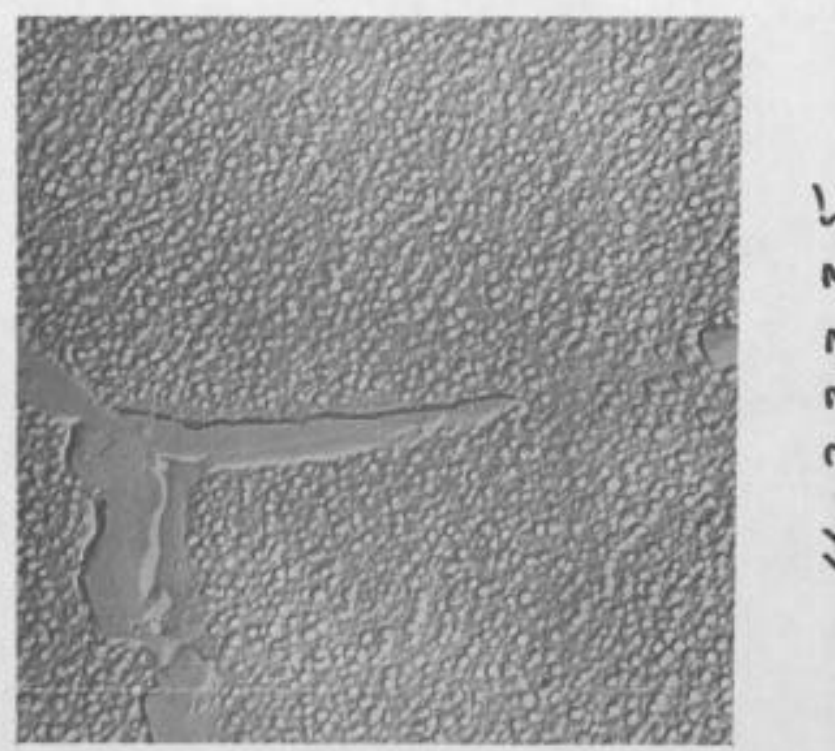

$500 \mathrm{X}$

3967 Hrs .

(d)

$25,000 x$

F1gure 8. MICROSTRUCTURE OF PYROMET 860 ALLOY AFTER EXPOSURE AT $1100^{\circ} \mathrm{F}$. Heat Treatment: 2955 Hrs. - A

Heat: 3

3967 Hrs. - C

Magnification: as indicated

Etchant: Light Microstructure - Glyceregla Electron M1crostructure - "G" 


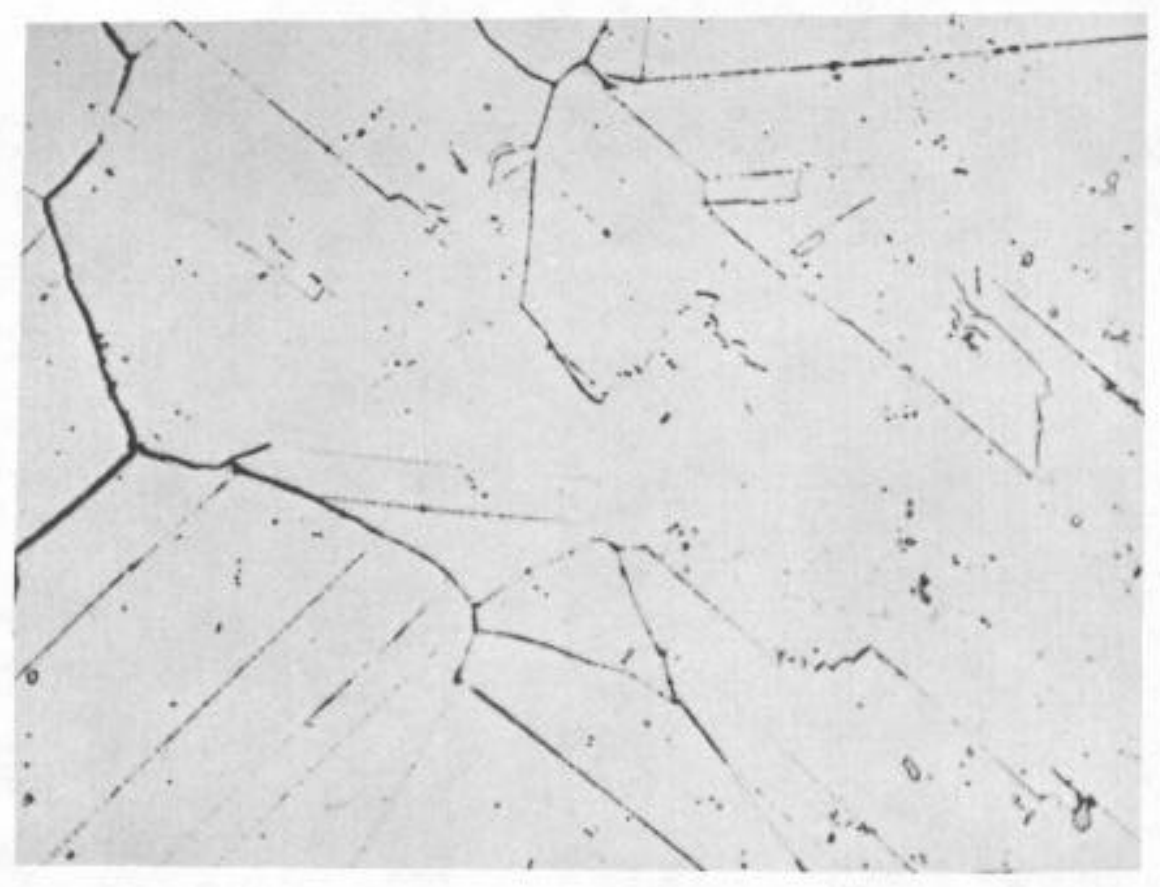

Figure 9. MICROSTRUCTURE OF STRESSED-REGION OF PYROMET 360 SPECIMEN AFTER EXPOSURE OF 3967 HOURS AT $1100^{\circ} \mathrm{F}$.

Heat Treatment: C

Heat: 3

Magnification: $500 x$

Etchant: Glyceregla 


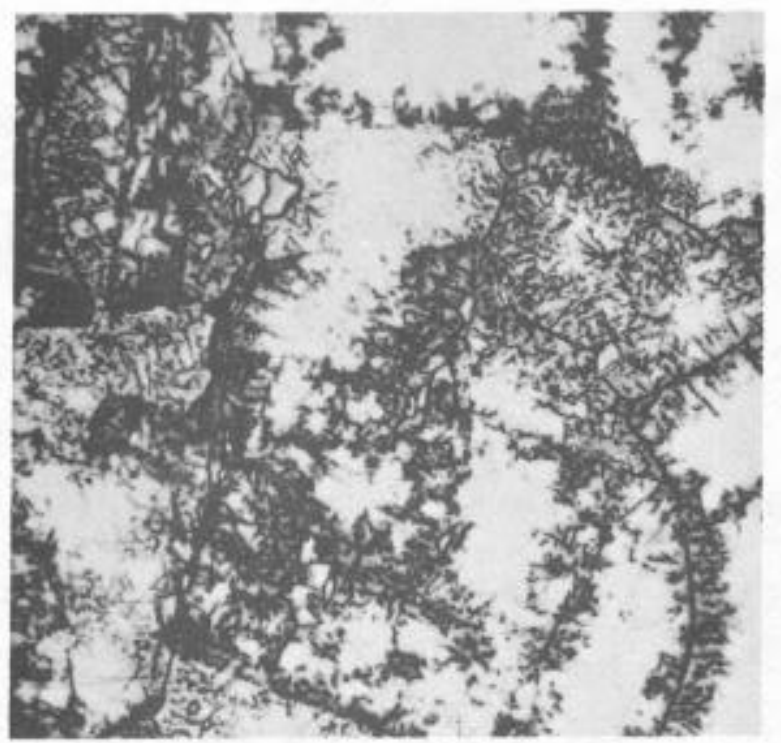

(a)

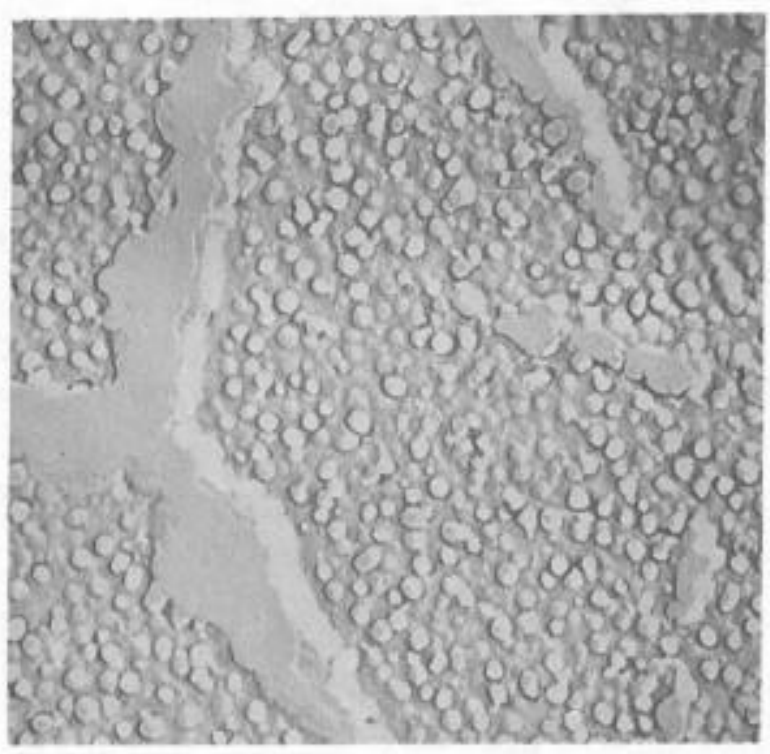

(c)

$25,000 x$

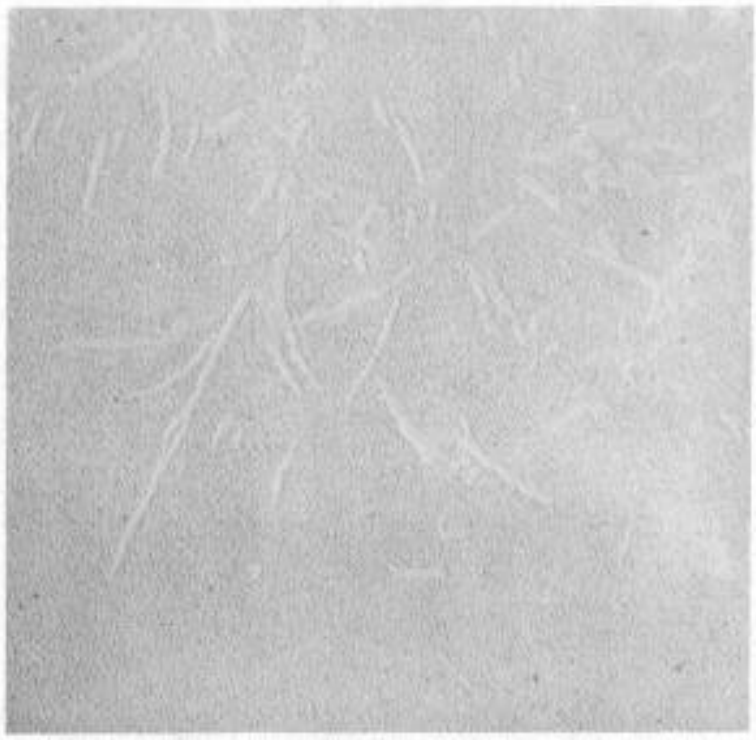

(b)

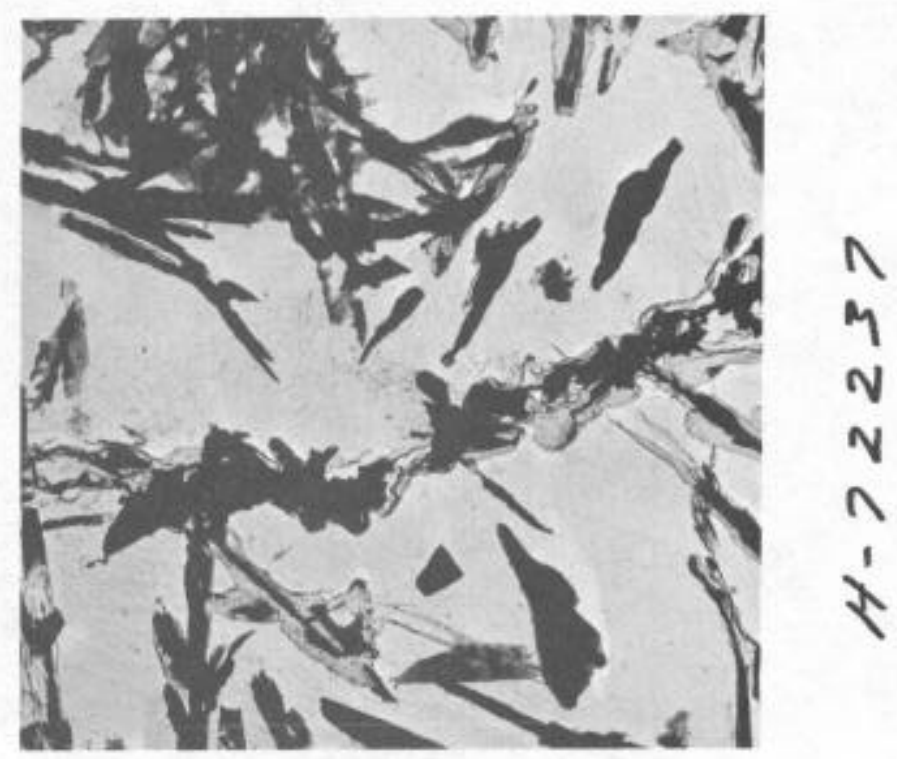

(d)

$10,550 \mathrm{x}$

F1gure 10. MICROSTRUCTURE OF PYROMET 360 ALLOY AFTER LONG-TIME $\left(37,660\right.$ HRS.) EXPOSURE AT $1200^{\circ} \mathrm{F}$.

Heat Treatment: A

Heat: 2

Magnif1cation: as 1ndicated

Etchant:

(a) Opt1cal M1crostructure - Glyceregia

b) \& (c) Electron Microstructure - "G"

(d) Extract1on M1crostructure - Glyceregia + $10 \% \mathrm{HCl}$ in alcohol 


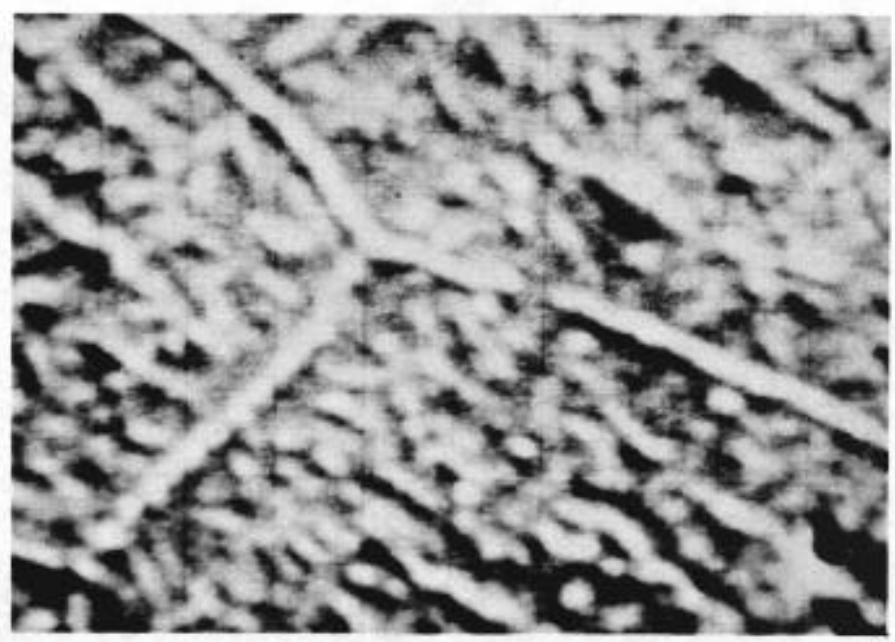

(a)

Back Scattered Electron Image $800 \mathrm{x}$

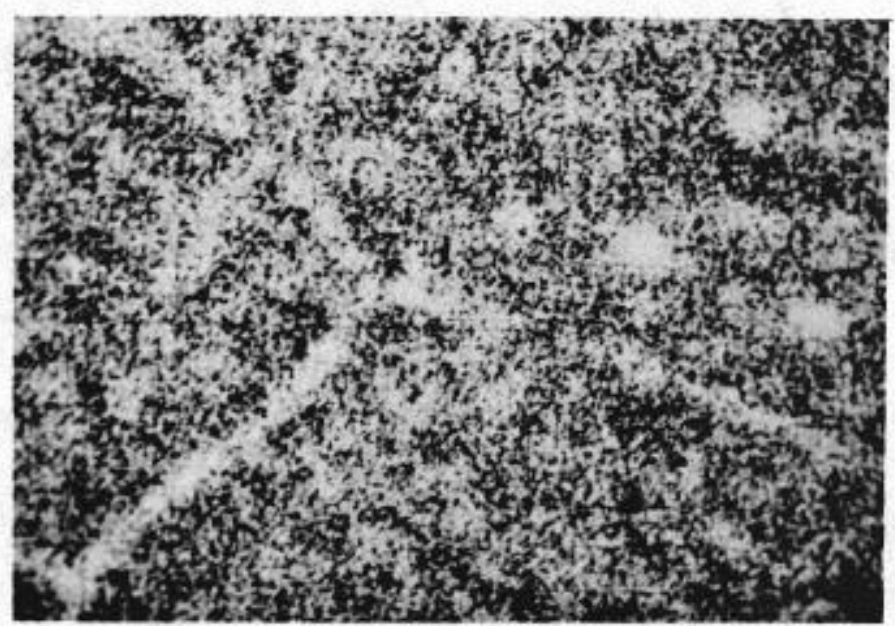

(b)

Mo L X-ray Image

F1gure 11. ELECTRON PROBE MICROANALYZER SCANNING MICROGRAPHS OF PYROMET 860 AFTER 37,660 HOUR EXPOSURE AT $1200^{\circ} \mathrm{F}$.

Heat Treatment: A

Heat: 2

Magnification: as 1ndicated

Etchant: None 


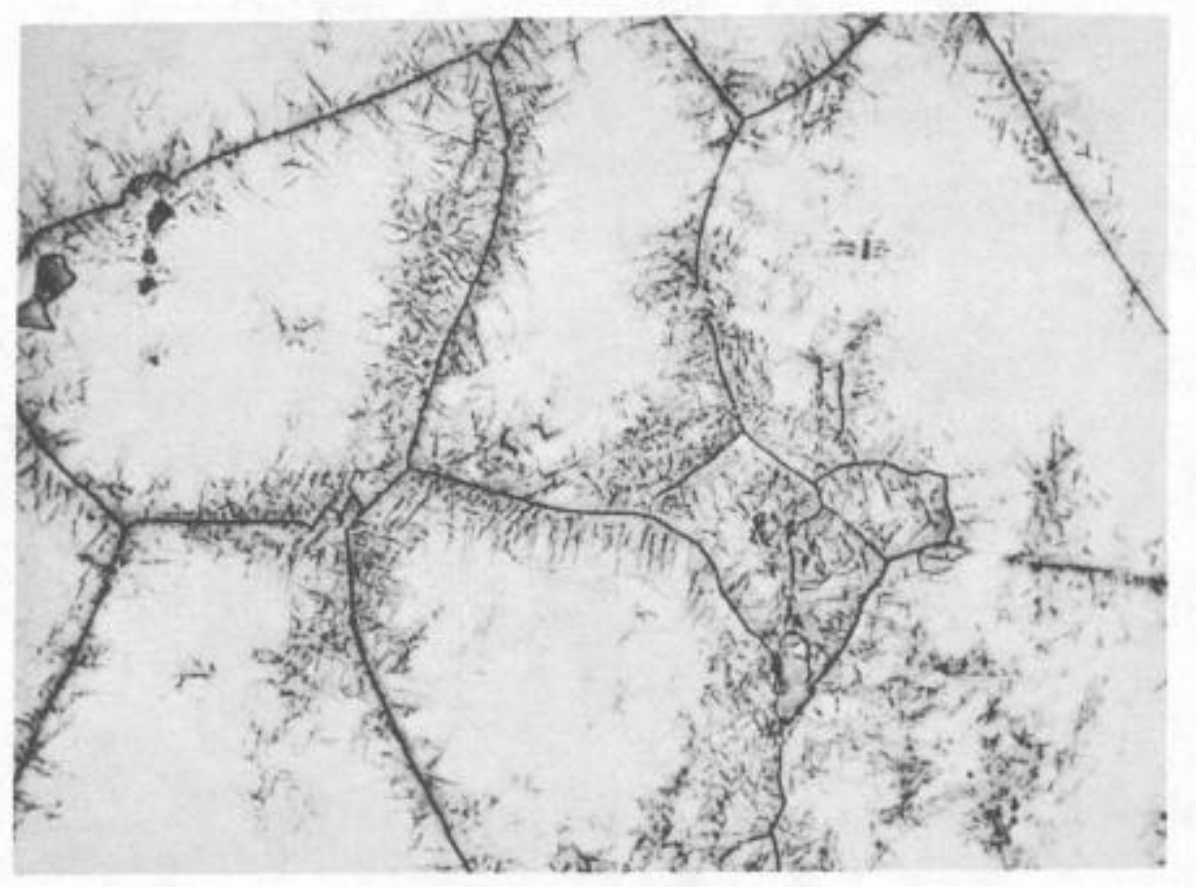

F1gure 12. OPTICAL MICROSTRUCTURE OF PYROMET 860 ALLOY AFTER EXPOSURE OF 14,230 HOURS AT $1300^{\circ} \mathrm{F}$. Heat Treatment: A Heat: 2 Magnification: $500 x$ Etchant: Glyceregla 


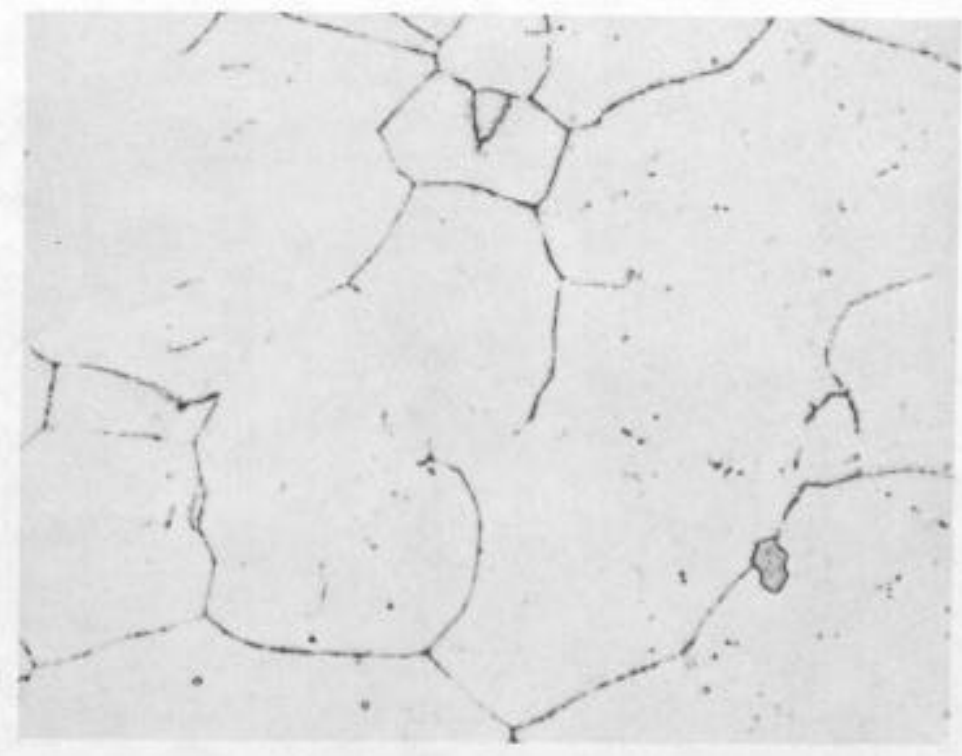

(a)

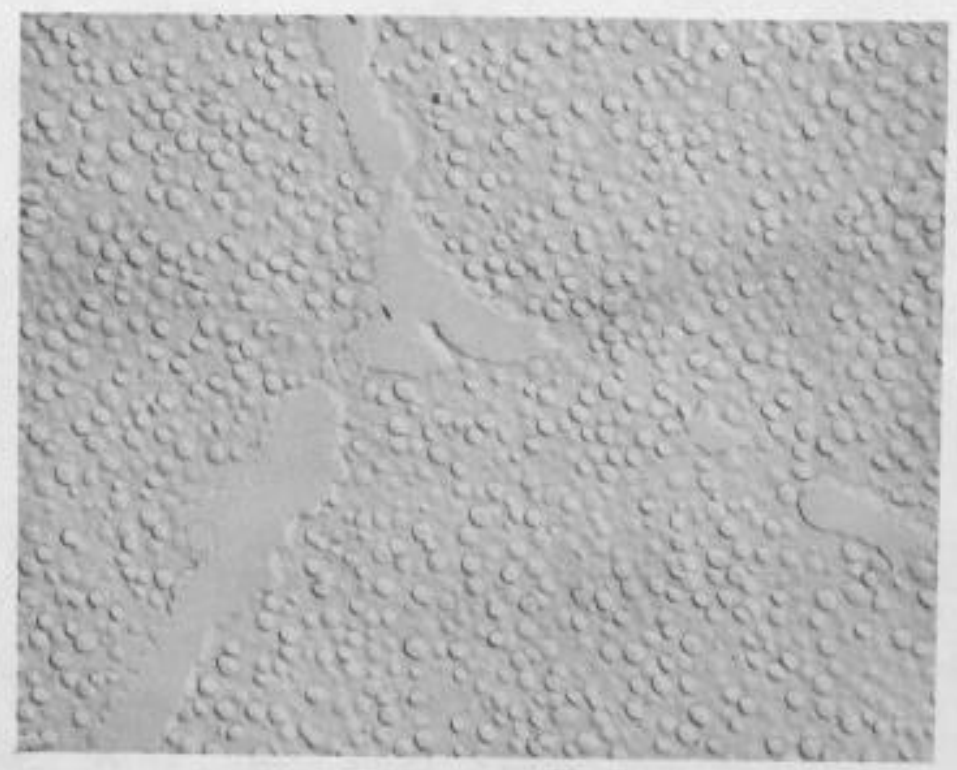

(b)

25, 000x

F1gure 13. MICROSTRUCTURE OF PYROMET 860 ALLOY AFTER EXPOSURE OF 671 HOURS AT $1350^{\circ} \mathrm{F}$.

Heat Treatment: A

\section{Heat: 3}

Magnification: as indicated

Etchant: Opt1cal Micrograph: Glycereg1a

Electron M1crograph: "G" 

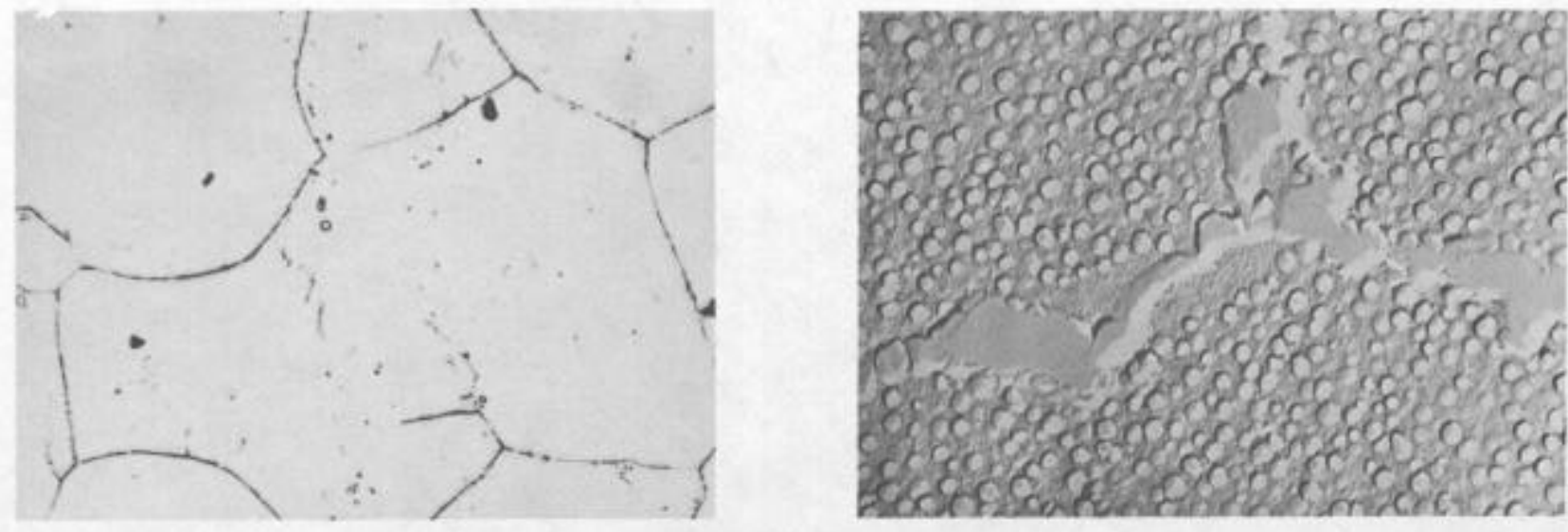

(a)

Thread End

(b)

$500 x$
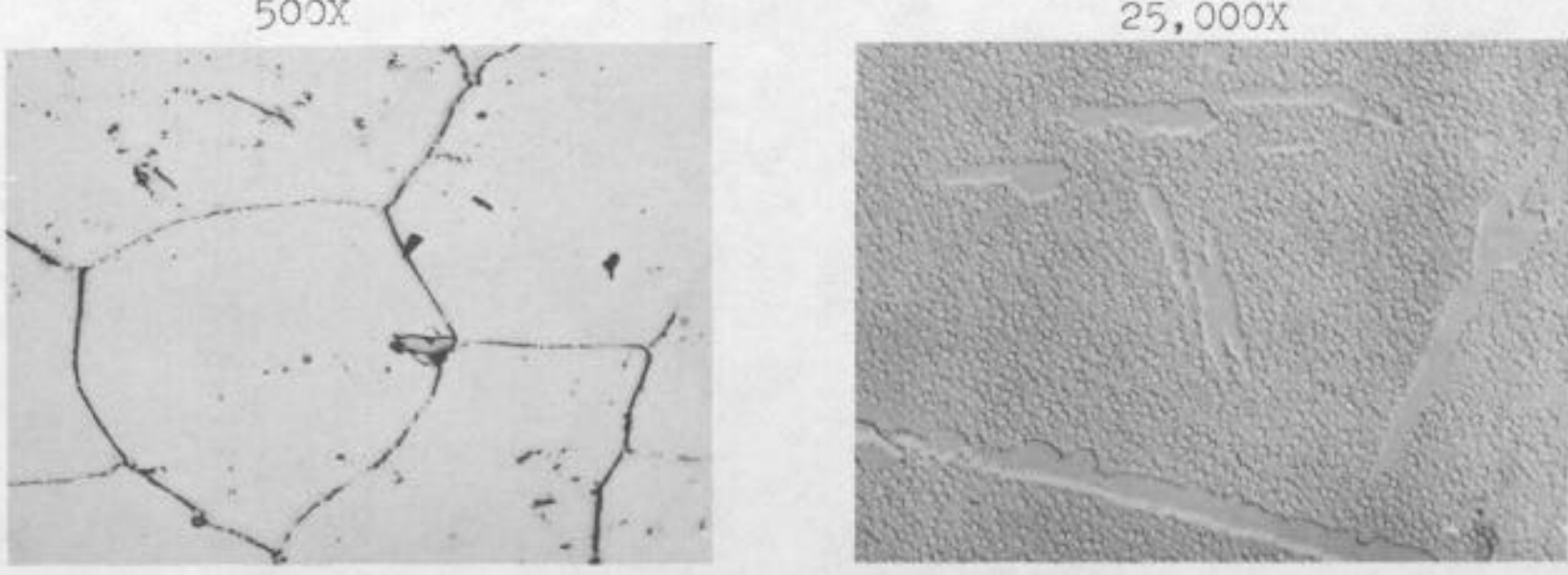

$\begin{array}{cc}\text { (c) } & \text { Stressed Fnd } \\ 500 \mathrm{X} & (50 \mathrm{ks} 1)\end{array}$

(d)

$12,500 x$

Figure 14.

MICROSTRUCTURE OF PYRONET 860 ALLOY AFTER EXPOSURE OF 1124 HOURS AT $1300^{\circ} \mathrm{F}$

Heat Treatment: C

Heat: 3

Magnification: as 1ndicated Etchant:

(a)\&(c) Opt1cal Microstructure Glyceregla

(d) \&(d) Electron Microstructure (e)

$5250 x$

Extraction Replica Stressed End (50 ks1)

(e) Extraction Microstructure Glyceregla + 10\% HCl in alcoh: 


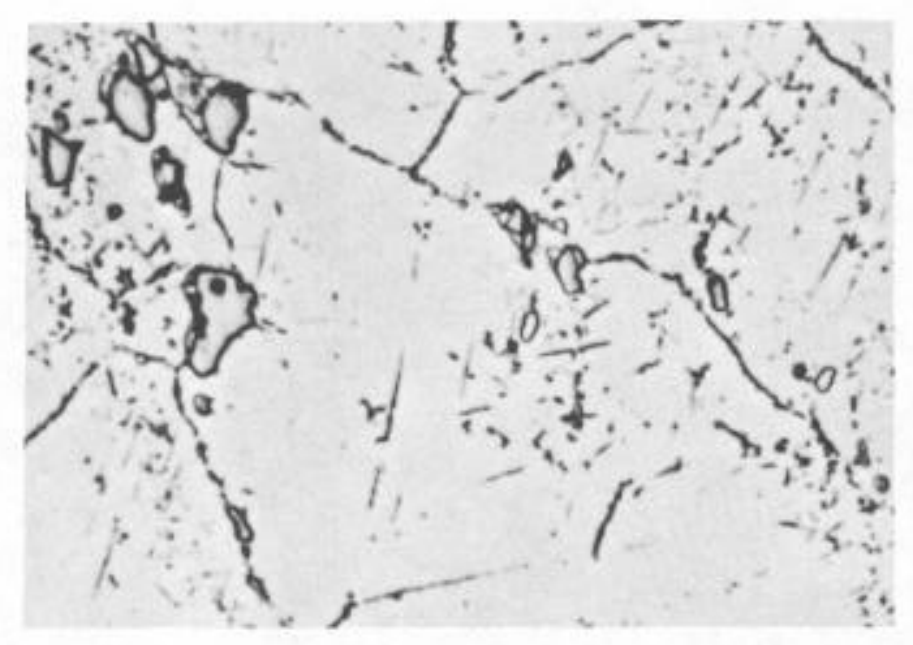

(a)

1000X

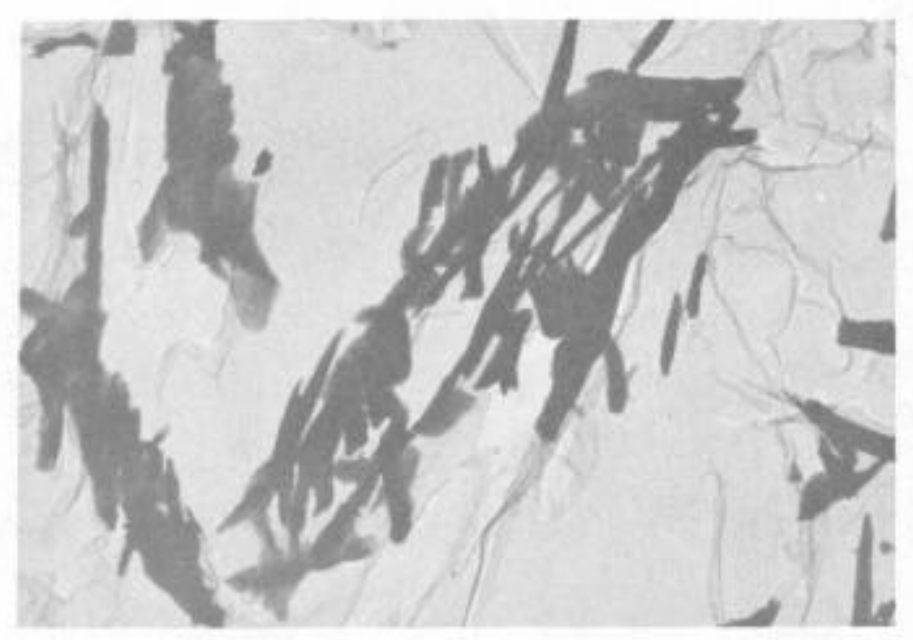

(b)

Extraction Replica - 25,000x

Figure 15. MICROSTRUCTURE OF PYROMET 860 AFTER EXPOSURE OF 541 HOURS AT $1400^{\circ} \mathrm{F}$.

Heat Treatment: A

Heat: 1

Magnification: as indicated

Etchant: Optical m1crostructure: Glyceregia

Extraction Microstructure: Glyceregia + 10\% HCl

in alcohol 


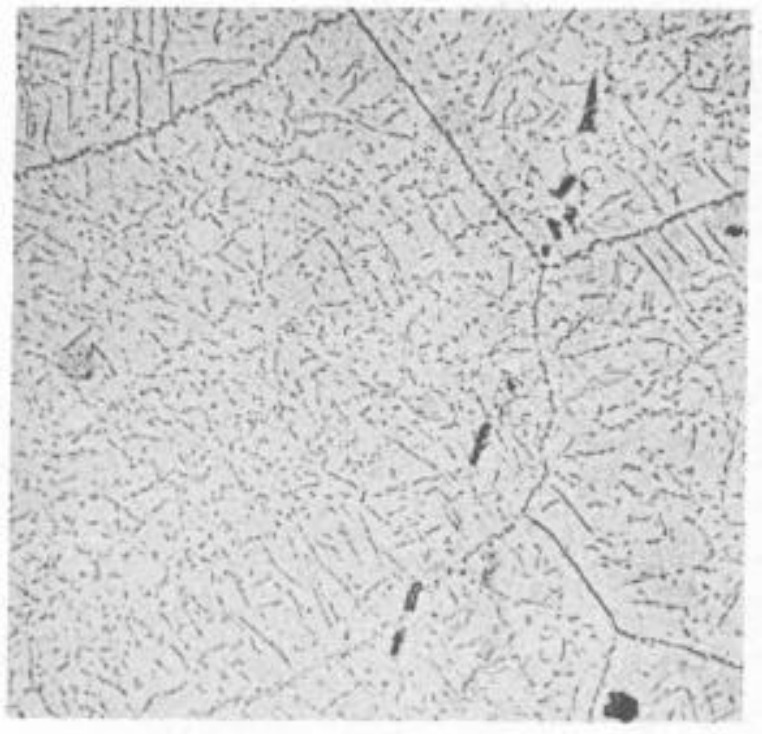

(a)

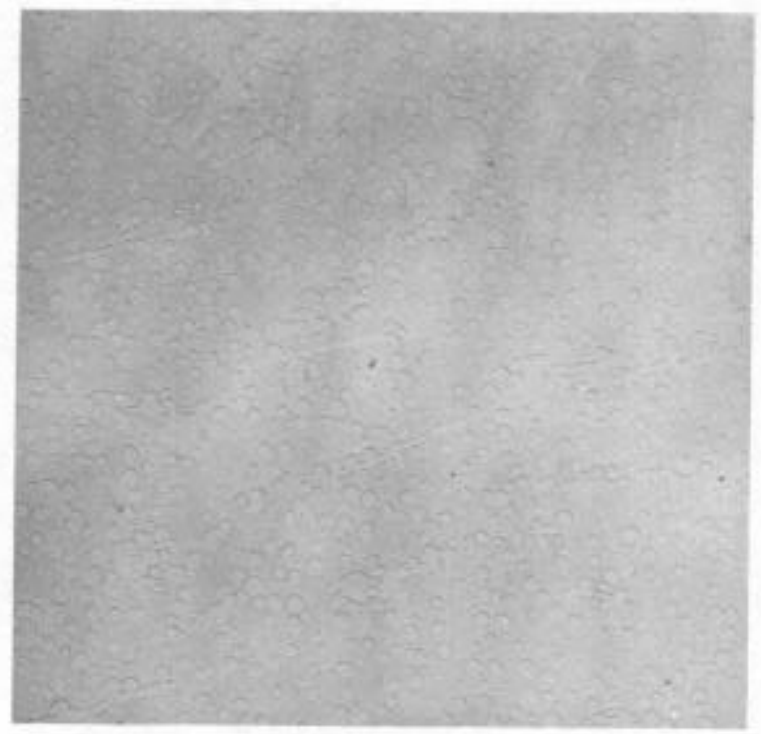

(b)

$6800 x$

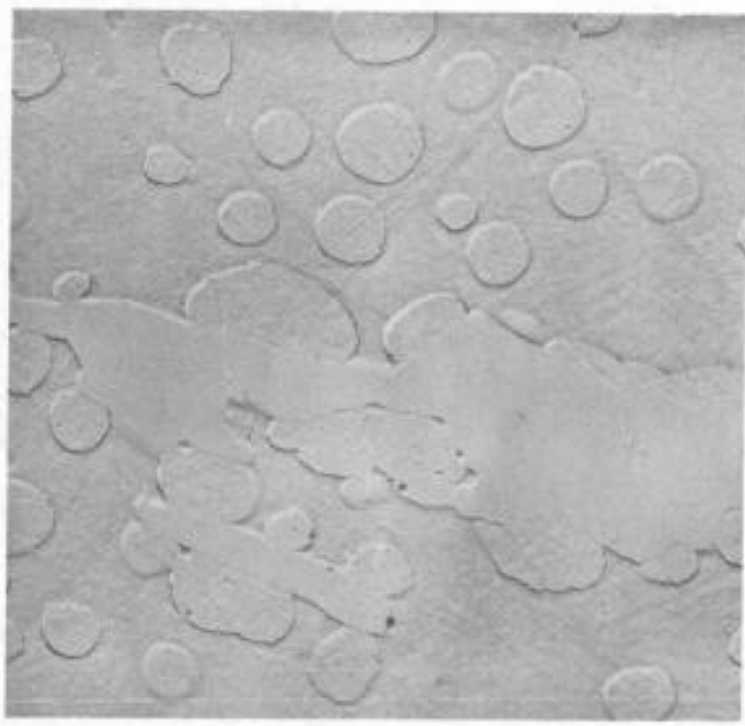

(d)

25, $000 x$

Figure 16. MICROSTRUCTURE OF PYROMET 360 ALLOY AFTER EXPOSURE OF 33,222 HOURS AT $1400^{\circ} \mathrm{F}$.

Heat Treatment: A

Heat: 2

Magnification: as indicated

Etchant: Optical Microstructure: Glyceregla
Electron Microstructure: "G" 


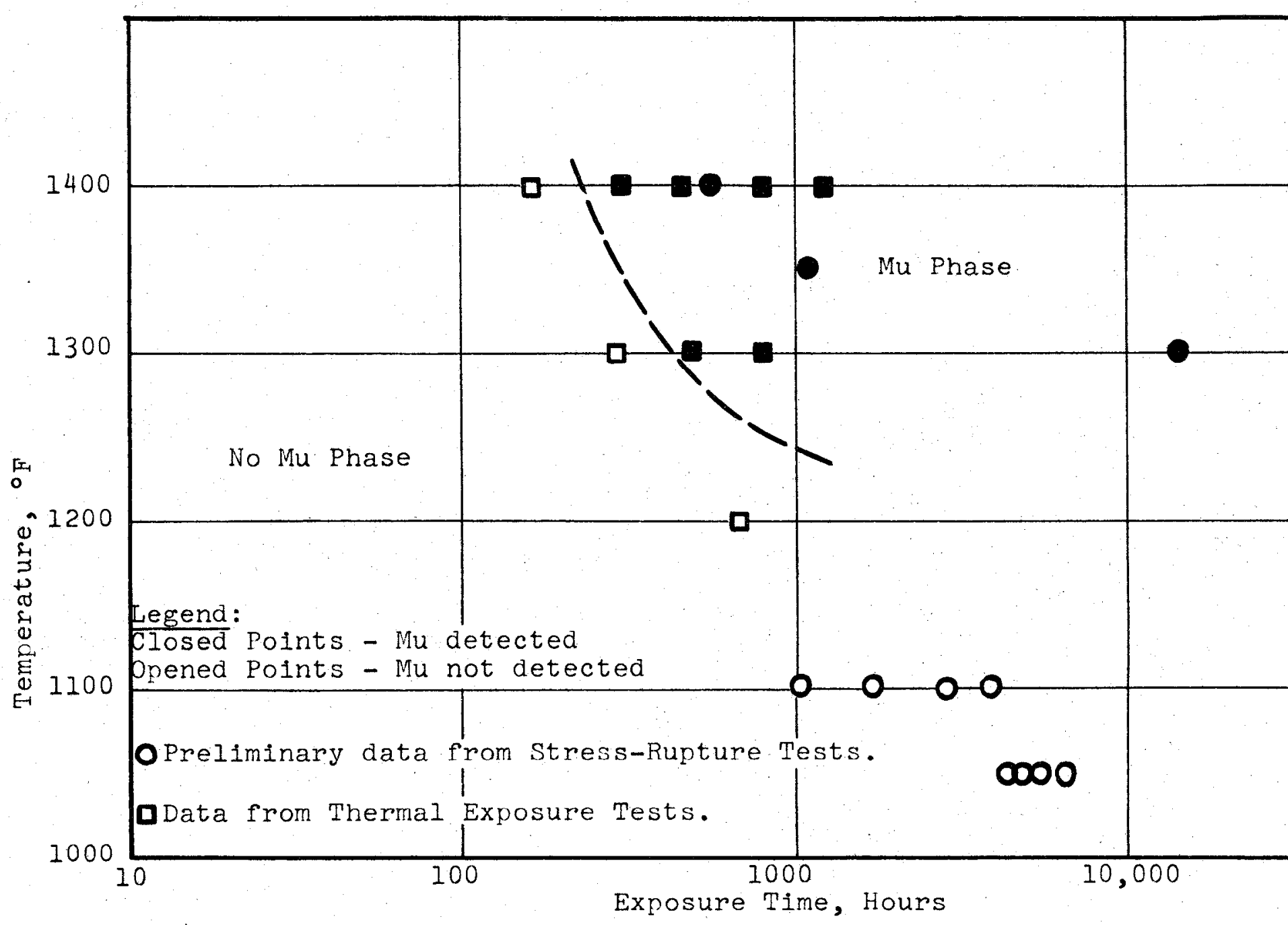

Fig. 17 TIME-TEMPERATURE BEHAVIOR OF MU PHASE FORMATION IN PYROMET 86 